\title{
CROSSTALK BETWEEN INVADOPODIA AND THE EXTRACELLULAR MATRIX
}

Shinji lizuka ${ }^{1,4}$, Ronald P. Leon ${ }^{1}$, Kyle P. Gribbin ${ }^{1}$, Ying Zhang ${ }^{2}$, Jose Navarro ${ }^{1}$, Rebecca Smith², Kaylyn Devlin², Lei G. Wang ${ }^{2}$, Summer L. Gibbs ${ }^{2,3}$, James Korkola ${ }^{2,3}$, Xiaolin $\mathrm{Nan}^{2,3}$ \& Sara A. Courtneidge $e^{1,2,3}$

Departments of Cell, Developmental and Cancer Biology ${ }^{1}$ and Biomedical Engineering ${ }^{2}$, Knight Cancer Institute ${ }^{3}$, Oregon Health and Science University, Portland, Oregon, USA

${ }^{4}$ Corresponding author (iizukas@ohsu.edu) 


\section{ABSTRACT}

2 The scaffold protein Tks5a is required for invadopodia-mediated cancer invasion both in vitro and

3 in vivo. We have previously also revealed a role for Tks5 in tumor cell growth using three-

4 dimensional (3D) culture model systems and mouse transplantation experiments. Here we use

5 both $3 \mathrm{D}$ and high-density fibrillar collagen (HDFC) culture to demonstrate that native type I

6 collagen, but not a form lacking the telopeptides, stimulated Tks5-dependent growth, which was

7 dependent on the DDR collagen receptors. We used microenvironmental microarray (MEMA)

8 technology to determine that laminin, collagen I, fibronectin and tropoelastin also stimulated

9 invadopodia formation. A Tks5a-specific monoclonal antibody revealed its expression both on microtubules and at invadopodia. High- and super-resolution microscopy of cells in and on

11 collagen was then used to place Tks5a at the base of invadopodia, separated from much of the

12 actin and cortactin, but coincident with both matrix metalloprotease and cathepsin proteolytic

13 activity. Inhibition of the Src family kinases, cathepsins or metalloproteases all reduced

14 invadopodia length but each had distinct effects on Tks5a localization. These studies highlight

15 the crosstalk between invadopodia and extracellular matrix components, and reveal the 16 invadopodium to be a spatially complex structure.

18 Keywords: Tks adaptors, proteases, invadopodia, actin, extracellular matrix, super-resolution microscopy 


\section{INTRODUCTION}

21 Cancer invasion, the ability of cancer cells to infiltrate into and through extracellular matrix (ECM),

22 has long been associated with tumor metastasis (Hanahan and Weinberg, 2011). Increasing evidence suggests that the same mechanisms that allow invasive capacity also promote tumor growth during cancer progression. This may be because the ECM acts as a physical barrier to tumor growth, which cancer cells destroy by activating pericellular proteases (Lu et al., 2012), Alternatively, these same pericellular proteases can release latent growth factors and cytokines in the matrix that promote tumor growth and angiogenesis (Chang and Werb, 2001). In either case, tumor growth and tumor metastasis are interlinked.

In many types of cancer, degradation of ECM has been linked to the formation of invadopodia (Murphy and Courtneidge, 2011; Weaver, 2008b), actin-rich plasma membrane protrusions coordinate the cytoskeleton with pericellular proteolytic activity. Since their discovery, invadopodia have been considered characteristic structures of invasive disease. Aside from an array of actin-regulatory proteins and signaling molecules, invadopodia also contain several classes of protease, including members of the metalloprotease superfamily (Chang and Werb, 2001; Seals and Courtneidge, 2003), serine proteases such as fibroblast activation protein (FAP) (Monsky et al., 1994) and urokinase-type plasminogen activator (UPA) and its receptor (UPAR) (Artym et al., 2002), and cysteine proteases such as cathepsins (Tu et al., 2008). Despite our steadily increasing knowledge of the composition and functions of invadopodia in vitro, much less is known about their in vivo presence and functional relevance in vivo. However, related podosome structures have been observed in motile vascular smooth muscle cells and neural crest stem cells in vivo (Murphy et al., 2011; Quintavalle et al., 2010), and genetically-defined

42 invadopodia have been observed during intra- and extra-vasation in animal models (Gligorijevic 43 et al., 2014; Leong et al., 2014) as well as in freshly explanted primary human tumors (Weaver, 44 2008a). 
Almost all of the components of invadopodia are also found in other actin-based structures such as adhesion complexes and protrusions (Murphy and Courtneidge, 2011). However, the Tks5 adaptor protein (SH3PXD2A) has a more restricted subcellular distribution, and is found predominantly at invadopodia (Saini and Courtneidge, 2018). Furthermore, knockdown of Tks5 prevents invadopodia formation and function (Abram et al., 2003; Buschman et al., 2009; lizuka et al., 2016; Seals et al., 2005). Conversely, enforced expression of the longest, $\alpha$ isoform of Tks5

52 in non-invasive cancer cells lacking native expression results in the formation of invadopodia

53 (Seals et al., 2005). Together these data support the conclusion that Tks5a is an obligate invadopodia scaffold, and its expression can be used as a surrogate to study invadopodia-based invasive capacity.

57 The Tks5 and related Tks4 adaptors are large scaffolding proteins composed of phosphatidylinositol lipid binding PX domains followed by 5 or 4 SH3 domains respectively. Both adaptors are Src substrates, and also contain multiple serine/threonine phosphorylation motifs. While we do not yet have a full understanding of all binding partners of the Tks adaptors, they have been implicated in reactive oxygen species (ROS) production (Diaz et al., 2009) and have been shown to interact with actin-remodeling proteins (Crimaldi et al., 2009; Oikawa et al., 2008; Stylli et al., 2009), pericellular proteases (Buschman et al., 2009), as well as the small GTPase Rab40b (Jacob et al., 2016), the guanine exchange factor Sos1, and the membrane remodeling GTPase dynamin (Rufer et al., 2009). The Oikawa lab has shown that invadopodium formation is initiated near focal adhesions by the binding of the Tks5a PX domain to $\mathrm{PI}, 4 \mathrm{P}_{2}$ (Oikawa et al.,

67 2008). This model was refined by Condeelis et al., who showed that small actin foci form in the absence of Tks5 (likely following Src phosphorylation of cortactin), and that Tks5 acts to stabilize 
bioRxiv preprint doi: https://doi.org/10.1101/2020.02.26.966762; this version posted February 27, 2020. The copyright holder for this preprint

(which was not certified by peer review) is the author/funder, who has granted bioRxiv a license to display the preprint in perpetuity. It is made available under aCC-BY-NC-ND 4.0 International license.

70 the structure and function of invadopodia formed in vitro in response to extracellular matrix, where

71 their full functionality is observed. Here we describe such experiments.

72

73 


\section{MATERIALS AND METHODS}

75

76

77

\section{Cell lines}

The luciferase-expressing human breast cancer cell line MDA-MB-231-Luc was obtained from Xenogen. The Src-transformed NIH-3T3 (Src3T3) cells have been described previously (Seals et al., 2005). The cell lines were routinely cultured in Dulbecco's minimal essential medium (DMEM) supplemented with $10 \%$ Fetal Bovine Serum (FBS) and a cocktail of penicillin and streptomycin (P/S) (Gibco). The human breast cancer cell lines, Hs578t and HCC1806, UACC812, SUM44PE, SUM52PE, HCC1187, SUM1315MO2, HCC1143, HCC1937, BT474 and HCC3153 were kindly provided by Dr. Joe Gray (Oregon Health and Science University [OHSU], USA). The culture medium used: SUM52PE (HAMS F12, 5\% FBS, 1 M HEPES, 1mg/mL hydrocortisone, 10mg/mL Insulin), HCC1187 (RPMI, 10\% FBS), SUM1315MO2 (HAMS F12, 10ug/mL EGF, 5\% FBS, 10mM HEPES, 5ug/mL insulin), HCC1143 (RPMI, 10\% FBS), HCC1937 (RPMI, 10\% FBS), BT474 (DMEM, 10\%FBS) and HCC3153 (DMEM, 10\%FBS).

\section{DNA constructs and shRNAs}

Human Tks5a was cloned into pCDH-CMV-MCS-EF1-Puro (Addgene) with a GFP sequence fused at the C-terminus. The shRNAs pLKO.1 lentiviral plasmids used for scrambled and human Tks5 knockdown were described previously (Blouw et al., 2015). The clones used were TRCN136336 (D5), TRCN0000136014 (D6) and TRCN0000136512 (D7). The shRNAs pLKO.1 lentiviral plasmids used for DDR1 and DDR2 knockdown were: TRC000121082 and TRCN0000361395. The plasmids encoding cortactin (\#26722), N-WASP (\#54199) and fascin (\#54094) were obtained from Addgene. Each insert was cloned into the lentiviral plasmid pCDHCMV-MCS-EF1-Puro with GFP fusion protein at C-terminus.

\section{Tks5 antibodies design and production}


The antibodies for Tks5 (Rabbit monoclonal, F4 and mouse monoclonal, G6) were generated by Abcam/Epitomics (F4) or by the Oregon Stem Cell Center, Monoclonal Antibody Core Facility at OHSU (G6), and validated by the Courtneidge laboratory. The following primer sets were used for cloning into pGEX-4T1 to produce the immunogens:

\section{PX domain (F4)-Forward: CGGGATCCATGCTCGCCTACTGCGTGCAG}

\section{PX domain (F4)-Reverse: CCGCTCGAGCTACTCTTTTGGAGGGTTGACATC}

\section{SH-linker (G6)-Forward: CTTCAGAGGATGTGGCCCTG}

\section{SH-linker (G6)-Reverse: CCTCACTCTTGGAGCCCTTG}

For Protein production: Appropriate DNA constructs were transformed into BL121 E.coli and a single colony was selected and grown overnight at $37^{\circ} \mathrm{C}$ in $5 \mathrm{~mL}$ of LB medium with ampicillin. The overnight culture was then added to $1 \mathrm{~L}$ of LB-ampicillin pre-warmed to $25^{\circ} \mathrm{C}$, grown in a shaking incubator at $25^{\circ} \mathrm{C}$ until OD600 was reached 0.5. Follow this, IPTG was added to a final concentration of $0.1 \mathrm{mM}$ and cultured overnight at $25^{\circ} \mathrm{C}$. The cells were pelleted in a centrifuge and lysed with lysis buffer $(20 \mathrm{mM}$ Tris $\mathrm{pH} 7.5,1 \%$ Triton, $1 \mathrm{mg} / \mathrm{mL}$ Lysozyme, $5 \mathrm{mM}$ DTT and protease inhibitor cocktail, Roche \#11-836-170 001) for 1 hour at $4{ }^{\circ} \mathrm{C}$. Lysed cells were placed in pre-cooled tubes in an ice bath, and sonicated at 50\% power with Sonic Dismembrator (Model 705, Fisher Scientific) with a micro-tip for 30 seconds, in 5 cycles. Lysates were centrifuged at $10,000 \mathrm{xg}$ for 5 minutes at $4{ }^{\circ} \mathrm{C}$ and the pellet was discarded. $5 \mathrm{~mL}$ of glutathione sepharose 4B was prepared according to manufacturer's instructions (GE \#17-0756-01) and added to the lysates, which were incubated at $4{ }^{\circ} \mathrm{C}$ on a rocking platform for 3 hours. The lysates were centrifuged at $500 \mathrm{xg}$ for $5 \mathrm{~min}$ at $4{ }^{\circ} \mathrm{C}$ and was washed in $50 \mathrm{~mL}$ of ice-cold $1 \mathrm{X}$ PBS for a total of three washes then re-suspended in a final volume of $20 \mathrm{~mL}$ of ice-cold PBS. An appropriate size of chromatography column (R\&D) was loaded with chilled sepharose beads at $4^{\circ} \mathrm{C}$ and allowed to settle. Lysate solution was added to the column and allowed to pass through the column by 
123

124

125

126

127

128

129

130

131

132

133

gravity. $5 \mathrm{~mL}$ of elution buffer $(50 \mathrm{mM}$ Tris $\mathrm{HCL}, 25 \mathrm{mM}$ glutathione, $\mathrm{pH} 8.0)$ was added to the beads, and this process was repeated for a total of 12-18 cycles. Eluates were collected at each cycle and kept on ice. To determine which elution contained the protein, samples of each elution were loaded onto a poly-acrylamide gel which was stained by coomassie-blue followed by destain (Thermo Fisher Scientific). Eluates that contained the appropriate proteins were pooled together in a pre-chilled tube on ice. Pooled eluates were concentrated in an Amicon Ultra (Millipore) centrifuge unit. Purified lysates were immediately frozen at $-80{ }^{\circ} \mathrm{C}$ to maintain integrity of proteins. GST tagged proteins were verified by immunoblot with an anti-GST antibody (\#717500, Zymed). Purified lysates were then sent to Abcam/Epitomics (F4), or to the Oregon Stem Cell Center, Monoclonal Antibody Core Facility at OHSU (G6) for production of monoclonal antibodies.

Immunizations for monoclonal antibody production at OHSU was conducted under a protocol approved by the OHSU Institutional Animal Care and Use Committee. Balb/C mice received multiple IP immunizations with the Tks5 protein. Four days after the final boost, mice were humanly euthanized using $\mathrm{CO} 2$ and their spleens were harvested. Splenocytes were fused with SP2/0 Ag14 myeloma cells (Kohler and Milstein, 1975) and hybrid cells were selected by growth in methylcellulose-containing HAT medium (Stem Cell Technologies). Approximately 600 clones were isolated and transferred to liquid HT medium in 96-well plates. Supernatants from these wells were initially screened for Tks5specific monoclonal antibodies by ELISA.

\section{Antibodies and reagents for immunoblotting and staining}

Antibodies used for immunoblotting were: F4 (1:10), G6 (1:500) and tubulin (T6557, Sigma, 1:3000). Antibodies used for immunofluorescence staining were: F4 (1:10), G6 (1:250) and tubulin 
147 (6074, 1:250, Sigma). Fluorescently labeled phalloidin (Alexa Fluor-350, -488, -568 or -647,

148 Thermo Fisher Scientific) was used for actin staining. Hoechst (1:4000, Thermo Fisher Scientific)

149 was used for nuclear staining.

Invadopodia assay on high-dense fibrillar type I collagen (HDFC)

152 Invadopodia staining was performed as previously described (lizuka et al., 2016). Briefly, cells were grown on glass coverslips with or without collagen and fixed with $4 \%$ paraformaldehyde/PBS (Electron Microscopy Sciences). For the invadopodia assay on collagen-coated coverslips, HDFC was prepared according to the original protocol reported (Artym, 2016; Artym et al., 2015). Briefly, $18 \mathrm{~mm}$ coverslips were pre-chilled on ice and coated with $10 \mu \mathrm{l}$ ice-cold neutralized collagen (\#35429, Corning). The pipette tip was used to spread the collagen evenly on the glass surface and the coated coverslips were left on ice for $10 \mathrm{~min}$ to facilitate flattening of the collagen. The layer of collagen was polymerized into a fibrillar meshwork at $37{ }^{\circ} \mathrm{C}$ for $30 \mathrm{~min}$, followed by centrifugation at 3,500 $\mathrm{g}$ for $20 \mathrm{~min}$. After fixation and permeabilization with $0.1 \%$ Triton $\mathrm{X}$ 100/PBS for 15 min, the cells were blocked by 5\% BSA in PBS with 5\% goat-serum for 1 hour at room temperature (RT) and incubated with primary antibodies for $90 \mathrm{~min}$ at RT (or overnight at 4 $\left.{ }^{\circ} \mathrm{C}\right)$. The cells were washed and incubated with Alexa Fluor-conjugated secondary antibodies and phalloidin. Confocal images were collected using a laser-scanning confocal microscope LSM880 equipped with AiryScan (Carl Zeiss). Images were transferred to Imaris ${ }^{\mathrm{TM}}$ (Bitplane) which is a multidimensional analysis program based on the fluorescence intensity data to create 3D view of

167 invadopodia and quantify invadopodia length, which was measured by Imaris software using the polygon scaling tool in Slice view. 
171 Type I collagen 3D cultures were performed as described previously (lizuka et al., 2016). For

172 collagen 3D proliferation assay, briefly rat-tail type I collagen (\#08-115, Sigma, Millipore) was

173 prepared to a final concentration of $2.1 \mathrm{mg} / \mathrm{ml}$, and 2,500 cells were added to the collagen mix

174 before gelling. For atelocollagen proliferation assay, rat-tail type I collagen or atelocollagen

175 (\#\#602, Yo Proteins) was prepared to a final concentration of $2.1 \mathrm{mg} / \mathrm{ml}$ and added to multi-well

176 plate for $1 \mathrm{hr}$ in a $\mathrm{CO}_{2}$ incubator. Spread cells were grown in DMEM containing $10 \%$ FBS. The

177 matrix was dissolved with $2 \mathrm{mg} / \mathrm{ml}$ collagenase type2 (\#LS004176, Worthington Biochemical

178 corporation) and cell numbers were quantified using hemocytometry. HDFC was prepared

179 according to original protocol reported in (Artym, 2016; Artym et al., 2015) and described briefly

180 above. The HDFC was dissolved with a $1: 1$ mixture of $2 \mathrm{mg} / \mathrm{ml}$ collagenase type2 and trypsin

181 (Gibco), and cell numbers were quantified using hemocytometry. For the growth assay in Matrigel

182 (BD Biosciences), briefly, the cells were added to Matrigel (1:1 dilution with serum-free medium)

183 on ice before gelling in a $\mathrm{CO}_{2}$ incubator for $30 \mathrm{~min}$. The cells in Matrigel were cultured in DMEM

184 containing 10\% FBS. The matrix was dissolved with cold PBS and cell numbers were quantified

185 by hemocytometry.

Invasion and growth assay and invadopodia staining in spheroids

188 3D spheroid cultures were performed as described previously (Kelm et al., 2003). Briefly, 189 spheroids of MDA-MB-231 cells were prepared in hanging droplets with 2,000 cells in $10 \mu \mathrm{l}$ of $19020 \%$ FBS containing DMEM for 3 days. The spheroids were embedded in $2.1 \mathrm{mg} / \mathrm{ml}$ of rat type I collagen (\#354263, Corning) and incubated with DMEM containing 10\%FBS for 2 days. Spheroids were fixed with $4 \%$ PFA and washed with PBS for three times. After permeabilization with $0.1 \%$ 
were collected and measured for the "spheroid size (actin intensity)". For invadopodia

197 visualization, spheroids were stained by Alexa Fluor-568-phalloidin and Hoechst (1:4000, Thermo

198 Fisher Scientific, used for nuclear staining). Imaging was performed on a laser-scanning confocal

199 microscope LSM880 equipped with AiryScan. Inhibitors used for the spheroid growth assay were:

200 GM6001 (EMD Millipore), CA074 (Vergent Biosciences) and DDR1-1N-1 (Selleck Chemicals).

\section{Microenvironmental Microarray (MEMA)}

MEMAs were produced as described previously (Smith et al., 2019; Watson et al., 2018) with several minor modifications. The same set of $45 \mathrm{ECM}$ or ECM combinations that we previously reported were plated into the bottom of 96 well plates (Ibidi). The plates were left desiccated for several days at room temperature, then 3000 MDA-MB-231 cells containing Tks $5 \alpha$ GFP were plated in $100 \mu \mathrm{L}$ DMEM containing $10 \%$ FBS. After overnight adhesion in a $37{ }^{\circ} \mathrm{C}$ incubator with $5 \% \mathrm{CO}_{2}$, an additional $100 \mu \mathrm{l}$ of DMEM containing PBS control, epidermal growth factor (EGF), with Alexa Fluor-568-phalloidin to visualize the invadopodia, which were also marked with

213 Tks5 $\alpha$ GFP, where double positive delineated invadopodia). Hoechst was used for staining of cell

214 nuclei. Imaging was performed on laser-scanning confocal microscope LSM880 equipped with 215 AiryScan.

\section{Super resolution microscopy}

218 MDA-MB-231 cells with Tks5 $\alpha$ GFP were cultured on HDFC prepared on \#1.5 coverglass for 2 
ChromoTek GFP Vhh, \# gt-250) using manufacturer recommended procedures. The GFPnanobody was conjugated to an oligonucleotide ('P1' docking strand) using published procedures

222 (Schnitzbauer et al., 2017). After staining, the cells were imaged sequentially, first with DNA-

223 PAINT (using a CF660R conjugated 'P1' imager strand) in buffer C, which contains 1x PBS 224 supplemented with $500 \mathrm{mM} \mathrm{NaCl}$. Each time after a cell was imaged with DNA-PAINT, the buffer 225 was replaced with 1x PBS supplemented with an oxygen scavenging mixture (comprising glucose 226 oxidase, catalase, and glucose) and $50 \mathrm{mM}$ 2-mercaptoethylamine (MEA) for STORM imaging 227 (van de Linde et al., 2011). For both DNA-PAINT and STORM imaging, a weak cylindrical lens $228(f=1000 \mathrm{~mm})$ was inserted in front of the detector (Andor iXon Ultra 897) for 3D single-molecule localization (Huang et al., 2008). DNA-PAINT and STORM imaging were performed on a custom setup as described previously (Creech et al., 2017), and 3D localizations were done using

231 ThunderSTORM (Ovesny et al., 2014).

\section{Activity-base probes (MMP-ABP, CTS-ABP)}

234 Cathepsin activity-base probe (CTS-ABP) were purchased from Vergent Bioscience and imaging 235 was performed according to manufacturer's instructions.

236 Chemical synthesis of MMP activity-based probe (MMP-ABP): SiTMR (Lukinavicius et al., 2013), 237 3-azido-1-propanamine (Hannant et al., 2010), and HxBP (Saghatelian et al., 2004) were synthesized following published protocols. To a solution of SiTMR (200 mg, $423 \mu \mathrm{mol})$ in DCM $(10 \mathrm{~mL})$ at room temperature, DiPEA (442 $\mu \mathrm{L}, 2.54 \mathrm{mmol}, 6 \mathrm{eq})$ was added. The reaction was stirred for 10 mins before HOBt (71 mg, $508 \mu \mathrm{mol}, 1.2 \mathrm{eq})$, 3-azido-1-propanamine (85 mg, 846 $\mu \mathrm{mol}, 2 \mathrm{eq})$ and EDC (97 mg, $508 \mu \mathrm{mol}, 1.2 \mathrm{eq})$ were added sequentially. The reaction mixture was covered from light and stirred overnight. The reaction was subsequently added saturated $\mathrm{NaHCO}_{3}$ and extracted with $\mathrm{DCM}(3 \times 50 \mathrm{~mL})$. The combined organic layers were rinsed with 
residue was purified by flash column chromatography with silica gel, using $\mathrm{DCM} / \mathrm{MeOH}$ as eluent

246 to give compound SiTMR-N $\mathrm{N}_{3}(173 \mathrm{mg}, 74 \%)$ as a pale green solid. Under $\mathrm{N}_{2}$, compound HxBP

247 (4.2 mg, $7.84 \mu \mathrm{mol})$ and SiTMR-N $3(5 \mathrm{mg}, 9.02 \mu \mathrm{mol})$ were suspended in $2 \mathrm{ml}$ degassed

$248 \mathrm{DMSO} / \mathrm{H}_{2} \mathrm{O}(1 / 1, \mathrm{v} / \mathrm{v})$. Freshly prepared $100 \mathrm{mM}$ sodium ascorbate solution $(95 \mu \mathrm{L})$ and copper

249 sulfate $\left(\mathrm{CuSO}_{4}\right)$ solution $(40 \mu \mathrm{L})$ were added to the solution. The resulting reaction mixture was

250 stirred at room temperature overnight and purified using preparative high-performance liquid

251 chromatography (HPLC, Agilent 1250 Infinity HPLC) with a C18 column $(150 \times 21.2 \mathrm{~mm})$. The

252 sample was eluted using solvents A: water-formic acid (99.9:0.1, v/v) and B: acetonitrile-formic

253 acid $(99.9: 0.1, \mathrm{v} / \mathrm{v})$, with the gradient increased from $10 \% \mathrm{~B}$ to $90 \% \mathrm{~B}$ over 60 mins at a flowrate

254 of $10 \mathrm{~mL} / \mathrm{min}$. The fractions containing product were frozen and lyophilized to afford MMP-ABP

255 (4.1 mg, 48\%) as a blue solid. HRMS (ESI-TOF) $\mathrm{m} / \mathrm{z}[\mathrm{M}+2 \mathrm{H}]^{2+}$ calculated for $\mathrm{C}_{60} \mathrm{H}_{71} \mathrm{~N}_{9} \mathrm{O}_{9} \mathrm{Si}_{2}$

256545.7645 , found 545.7658. Synthetic route, structure and purity confirmation of MMP-ABP is

257 shown in Supplementary Figure S1. 


\section{RESULTS AND DISCUSSION}

\section{New reagents to study Tks5 isoforms}

260 There are multiple isoforms of Tks5, generated by alternative promoter usage (Cejudo-Martin et

al., 2014; Li et al., 2013). The full length ( $\alpha$ ) isoform contains the amino terminal PX domain

(Figure 1A) required for phosphatidylinositol lipid binding and the formation of invadopodia (Seals human cells. To overcome these limitations, we generated new Tks5 antibodies to assist in the study of invadopodia. Of these, F4 is a rabbit monoclonal antibody (produced in collaboration with Epitomics, Inc.) raised against an epitope in the PX domain of Tks5a, and G6 is a mouse monoclonal antibody (produced in collaboration with the Flow Cytometry Shared Resource at OHSU) raised against an epitope in one of the unique linker domains of Tks5. The specificity of these antibodies in immunoblotting is demonstrated in Figure 1B. G6 recognizes both full-length and PX domain-deleted forms of Tks5 (e.g., the $\alpha$ and $\beta$ isoforms) in human cells, whereas F4 recognizes only the full-length $\alpha$ isoform of Tks5. Neither antibody recognized the related Tks4

275 protein.

276 Given our interest in the role of invadopodia in breast cancer, we next used the G6 ("panTks5") 277 antibody to profile a series of invasive human breast cancer cell lines. All tested cell lines 278 expressed predominantly Tks5a, with low levels of Tks5 $\beta$ and short also detected in some cell

279 lines (Figure 1C). We examined expression by immunofluorescence in one of these cell lines, 280 MDA-MB-231. Focusing on the ventral surface of the cell, we noted co-localization of G6 with the 281 puncta of F-actin characteristic of invadopodia, as expected, whereas no staining was seen if 282 Tks5 expression was reduced by RNA interference (Figure 1D). The F4 antibody also showed 
specific staining at invadopodia in these cells (Figure 1E). Thus, we conclude that these antibodies are suitable for both immunoblotting and immunocytochemistry. We also found them to provide suitable utility for immunoprecipitation and immunohistochemistry (data not shown). We next used F4 for high-resolution imaging of Tks5a in Src-transformed mouse fibroblasts (Src3T3), a workhorse for studies on invasive behavior in which the invadopodia form into characteristic rosettes (Chen, 1989; Tarone et al., 1985). Here too we observed Tks5a colocalization with F-actin in the rosettes (Figure 1F). However, in these cells, the relative lack of actin stress fibers, coupled with our use of high-resolution microscopy, also allowed us to observe punctate staining of Tks5a in the cytoplasm. Interestingly, in the cytoplasm Tks5a staining was coincident with tubulin, but not actin, suggesting that Tks5a is localized to microtubules as well as invadopodia. Similar distribution was observed when Tks5a fused with GFP or mCherry was expressed in the cells. This analysis also revealed that the microtubules terminated near the rosettes, in keeping with other reports on podosomes and invadopodia (Linder et al., 2011; on microtubules, which indeed we have now observed (studies to be reported elsewhere).

\section{Morphology and growth of breast cancer cells with and without Tks5.}

The ECM, particularly collagen-I, can control cell survival, proliferation, migration and invasion. In cancer, collagen-I had been thought to be growth suppressive (Henriet et al., 2000), but this view is now more nuanced (Keely, 2011; Pickup et al., 2014). For example, increased collagen-I density and changed ECM architecture promote tumor proliferation and metastasis and are linked to a worse clinical outcome (Schedin and Keely, 2011). In addition, ECM rigidity has been shown to promote invadopodia formation (Parekh et al., 2011) and high-density fibrillar collagen (HDFC) in particular increased invadopodia formation in the MDA-MB-231 breast cancer cell line (Artym et al., 2015). 
We have previously published that Tks5 knockdown is not required for growth of either breast cancer or melanoma cells on tissue culture plastic, but has an inhibitory effect when cells are placed in a cross-linked matrix of type I collagen (collagen-I) (Blouw et al., 2015; lizuka et al., 2016). An example of this finding is shown in Figure 2A. Over the course of this five-day assay, control cells increased in number approximately 10 -fold, but knockdown of Tks5 with two different shRNAs had a marked inhibitory effect. Interestingly, the basement membrane surrogate Matrigel stimulated growth only three-fold over the same time period, although Tks5 knockdown was still inhibitory. We next wanted to explore whether the ability of collagen-I to form cross-links was important for the observed growth stimulation. To do this we compared native collagen to a pepsinized version which lacked the telopeptides where cross-linking occurred (Figure 2B). We found that, compared to controls, atelo-collagen only poorly stimulated growth, independent of Tks5 expression (Figure 2C). Atelocollagen was also unable to promote invadopodia formation in MDA-MB-231 cells and two other invasive breast cancer cell lines, Hs578t and HCC1806, when compared to native collagen-I (Figure 2C). These data are consistent with a report that fibrillar collagen-I induced an invasive phenotype in breast cancer cells whereas high-density non-fibrillar collagen-I (generated by sonication to shear fibrils) suppressed invasive behavior (Maller et al., 2013). tyrosine kinases DDR1 and DDR2 (Leitinger and Hohenester, 2007), with the DDRs attracting recent attention as possible therapeutic targets (Brakebusch and Fassler, 2005; Rammal et al., 2016; Valiathan et al., 2012). DDR1 is reported to have a kinase-independent function in 331 linearizing invadopodia (Juin et al., 2014). There are no reports on DDR2, although interestingly 332 DDR2 is involved in hypoxia-stimulated invasion of cancer cells (Ren et al., 2014), through 333 stabilization of Snail and subsequent EMT (Zhang et al., 2013). Hypoxia increases invadopodia 334 formation (Diaz et al., 2013), as does Twist-stimulation (Eckert et al., 2011). This suggests a 
possible reciprocal relationship between invadopodia and collagen-DDR signaling. We used two approaches to investigate this. First, we knocked down DDR1 and DDR2, and tested the effect on growth on and in collagen-I. In both cases we observed a reduction in collagen-I stimulated growth, to the same extent as Tks5 knockdown (Figure 2D). Secondly, we evaluated the effect of the DDR inhibitor DDR1-IN-1, which inhibits both DDR1 and DDR2 at the concentrations used (Kim et al., 2013). We observed a reduction in the invasion and growth of breast cancer cells in 3D (using a spheroid assay), but not 2D growth (Figure 2E, not shown). Together, these data highlight the importance of DDR signaling in invadopodia formation. It is likely that many of these effects occur through DDR2, which is uniquely activated by fibrillar collagen-I (Itoh, 2018; Rammal et al., 2016), whereas DDR1 can be activated by both collagen-I and collagen-IV lacking fibrillar structure. This will be explored in more detail in future work.

\section{The effect of ECM on invadopodia formation.}

Research in recent years has highlighted the importance of the tumor microenvironment on invadopodia formation and function, but efforts to systematically evaluate how the growth factors, cytokines and chemokines, secreted by multiple different cell types. With these issues in mind, the Korkola laboratory has developed the microenvironmental microarray (MEMA) technology to enable study of the microenvironment (Watson et al., 2018). MEMA consist of arrayed combinations of ECM molecules printed into each well of a multi-well plate, where each printed ECM spot forms a growth pad upon which cells can be cultured. Each individual well is

357 treated with a separate soluble growth factor or ligand. By performing these assays in a multi-well 358 format, the effects of unique combinations of ECM plus ligand can be assessed for their effects 359 on cellular phenotypes (Watson et al., 2018). We ran a small-scale MEMA experiment using MDA- 
replaced by similar levels of Tks5aGFP. We used 45 different ECM proteins, with either no ligand, EGF, FGF or HGF, for a total of 192 different conditions in this screen. After 24 hours of growth, cells were fixed and stained with phalloidin for F-actin visualization and Tks5a co-localization on a confocal microscope (Figure 3). As expected, we observed collagen-I stimulation of invadopodia formation. We also observed stimulation by laminin, consistent with known biology and the observation that invadopodia form at contact sites with basement membrane

367 (Schoumacher et al., 2010). We also saw more invadopodia on fibronectin, an abundant ECM 368 protein with appreciated roles in cancer (Rick et al., 2019). But the most prominent ECM inducer of invadopodia was tropoelastin, the soluble precursor of the cross-linked ECM protein elastin

370 (Vindin et al., 2019). As the name suggests, elastin provides elasticity and resilience to many organs, including the breast and the lung (a frequent site of breast cancer metastasis). Pericellular proteolysis of elastin can impact several aspects of cancer progression (Scandolera et al., 2016), although a discrete role in invadopodia biology has not previously been reported. None of the added growth factors were found to impact invadopodia formation in this MEMA assay format (not shown). This small-scale study demonstrates the feasibility of MEMA to identify novel modulators of invadopodia. In the future, it will be important to also test the roles of their corresponding receptors and downstream signaling events on invadopodia biology.

\section{Spatial distribution of Tks5a and other invadopodia components.}

380 Previous studies have started to reveal fundamental properties of invadopodia such as molecular components, order of assembly, and overall architecture. Currently, it is thought that invadopodia

382 formation begins with a 'core' of branching cortical actin (with actin, cortactin, N-WASP, cofilin 383 and so on), likely through Src-mediated tyrosine phosphorylation of cortactin, followed by 384 recruitment of SHP2 and Tks5a (Oikawa et al., 2008; Sharma et al., 2013). SHP2 generates $385 \mathrm{PI}(3,4) \mathrm{P} 2$, which binds to the PX domain of Tks5 $\alpha$ to turn the latter into a multi-functional scaffold 
to: bind to and stabilize filamentous actin; allow protrusion extension and maturation; engage and activate proteases such as the ADAMs and potentially MMPs for proteolytic activities; and recruit other adaptor proteins such as Nck2 and dynamin-2, which help organize signaling molecules such as the integrins, EGFR, and MET. While recruitment of these proteins and lipids could explain the various biological functions of invadopodia, the prior studies have mostly used 2D culture systems (e.g., on coverslips with or without a thin layer of gelatin). The structure and dynamics of invadopodia in more physiological 3D growth conditions remain poorly defined. We have conducted a series of experiments to define invadopodia in native collagen-I. Unexpectedly, both in tumor cell spheroids in 3D and cells on HDFC, Tks5a localization was restricted at the base of invadopodia but not in the protrusion body itself (Figure 4A, B, E and Supplementary movie1). We have also used super-resolution microscopy (SRM) to image Tks5 and the results revealed even more details of Tks5a distribution at the base of invadopodia, resembling that of the actin cortex (Figure 4D and E). Since Tks5 likely acts as a scaffold for multiple proteins, this localization pattern might also confine relevant biological processes to the base of invadopodia.

We next evaluated the spatial distribution of the invadopodia components and actin regulators cortactin, N-WASP and fascin HDFC. To do this, cortactin, N-WASP or fascin-GFP fusion proteins were overexpressed in MDA-MB-231 cells together with Tks5a-mCherry, and the localization of these proteins in invadopodia formed on HDFC evaluated (Figure 5A, B). First, we confirmed that Tks5aGFP and Tks5a-mCherry were colocalized at the base of invadopodia. N-WASP accumulated in similar areas to Tks5a, consistent with reports of their association between $\mathrm{N}$ WASP and Tks5 (Oikawa et al., 2008). However, cortactin, which has also been reported to associate with Tks5a (Crimaldi et al., 2009), extends much further into the invadopodia body than Tks5a. Finally, while there was no localization or accumulation of fascin in invadopodia at day 2 
411 are schematized in Figure 5C. It will be important to extend these observations to other

412 invadopodia proteins in the future, and to look at the ultrastructure of the F-actin contained in

413 invadopodia over time. However, these observations may suggest that fascin-directed actin

414 cables only form once the protrusions have fully elongated.

\section{Localization and function of pericellular proteases}

417 Invadopodia are known to be sites of pericellular proteolysis, with matrix, cysteine and serine 418 protease activity associated with them, although whether protease activity is required for invadopodia formation, or just for function, may be cell type and context dependent (Linder, 2007; Murphy and Courtneidge, 2011). Nor have 3D studies of proteolytic activity associated with

421 invadopodia been performed. We have begun to investigate this by determining the localization

422 of both the MMPs and the cysteine cathepsins, initially focusing on their proteolytically active 423 forms, using activity based probes (ABPs) for cathepsins (Xiao et al., 2013) and MMPs 424 (Saghatelian et al., 2004). In both cases, active enzyme was localized to the base of invadopodia, 425 in approximately the same location as Tks5a in magnified orthogonal views (Figure 6A and C). $4263 \mathrm{D}$ sideview of invadopodia more clearly showed the spatial localization of those proteins 427 (Figure6B, 6D, Supplementary movie2 and movie3). This was surprising, since it might have 428 been expected that ECM degradation occurs at the advancing tip of the invadopodium. It has 429 been shown that pericellular proteases can be delivered as exosome cargo to invadopodia 430 (Hoshino et al., 2013). In the future, it will be interesting to visualize exosomes and other 431 microvesicles in these 3D systems.

433 We next looked at the requirement for metalloprotease and cysteine cathepsin activity for 434 invadopodia formation, using small molecule inhibitors. We found that 3D growth was affected by 435 the MMP inhibitor GM6001 and the impermeable cathepsin inhibitor CA074 (Figure 7A). These 
data suggest non-redundant, or concerted, functions for these two classes of protease. We used our high-resolution microscopy techniques to investigate further, comparing to a Src family kinase (SFK) inhibitor SU11333 (Laird et al., 2003), a derivative of SU6656 (Blake et al., 2000), since many invadopodia proteins are Src substrates (Murphy and Courtneidge, 2011). SFK inhibition markedly reduced the Tks5a content at the base of nascent invadopodia, whereas MMP and cathepsin inhibition caused an increase in Tks5a content (Figure 7B and C). We confirmed these observations by plotting signal intensities with z-stack depth (Figure 7C, right). SFK inhibition reduced both actin and Tks5a signals at invadopodia (Y-axis), but MMPs/cathepsin inhibition increased Tks5 $\alpha$ accumulation at invadopodia compare to the DMSO control group. These graphs also show the decrease of protrusion depth (X-axis, actin intensity) in all inhibitor groups. To test the formation of functional invadopodia on HDFC, the length of invadopodia was measured. We found that all inhibitors markedly reduced the length of protrusions (Figure 7D). Thus, we speculate that SFK signaling may be required for initiation and perhaps maintenance of protrusions, whereas MMPs and cathepsins may promote the maturation/elongation of the structures.

\section{CONCLUSIONS}

In conclusion, we describe here two new antibodies: one (G6) recognizes all isoforms of Tks5; and one (F4) is specific for Tks5a. Both have antigen recognition utility in multiple formats

455 including immunoblotting, immunoprecipitation and immunostaining (both immunohistochemistry 456 and immunocytochemistry), making them highly valuable to the invadosome community.

457 Combining these antibodies with several cutting-edge technologies such as super-resolution 458 microscopy, MEMA and activity-based probes, we have begun to investigate the structure and 459 function of invadopodia forming in response to the ECM. The results revealed new and complex 460 sub-invadopodia architecture unseen in our previous analyses in 2D, and ECM components 461 (tropoelastin) as novel invadopodia inducer. Among others, it is possible to evaluate whether 
462 invadopodia architecture is influenced by the ECM components present by studying invadopodia

463 structure in 3D or semi-3D model systems. The 3D and HDFC formats also revealed that ECM

464 stimulates cancer cell growth in an invadopodia-dependent manner, which goes a long way to

465 explaining why Tks5a (and other invadopodia proteins) are required for growth of many invasive

466 cancer cells in 3D, but not when the same cells are cultured on tissue culture plastic.

467 Future studies will expand on the findings described herein, with the goals being to evaluate more 468 invadopodia components, to map their localizations, interactions and functionality. These studies 469 will be important to determine whether invadopodia initiators such as the DDR receptors co470 localize to invadopodia, as well as the spatial localization of their downstream signaling 471 components.

\section{ACKNOWLEDGMENTS}

474 We acknowledge the expert assistance of Dr. Stefanie Kaech Petrie and Crystal Chaw (cell 475 imaging) in the Advanced Multiscale Microscopy Shared Resource, Dr. Philip R Streeter and 476 YongPing Zhong (G6 antibody production) Oregon Stem Cell Center, Monoclonal Antibody Core, 477 and Dr. David Kilburn (MEMA preparation) in the Department of Biomedical Engineering, Knight 478 Cancer Institute at the OHSU. We also thank Dr. Ting Zheng for assistance with conjugating 479 antibodies used in DNA-PAINT experiments.

480 This work was supported in part by the National Institutes of Health grant R01 CA217625 and 481 support from the Knight Cancer Institute (SAC), Brenden Colson Center for Pancreatic Care at 482 OHSU (SLG). 
Abram, C.L., Seals, D.F., Pass, I., Salinsky, D., Maurer, L., Roth, T.M., Courtneidge, S.A., 2003.

The adaptor protein fish associates with members of the ADAMs family and localizes to podosomes of Src-transformed cells. J Biol Chem 278, 16844-16851.

Artym, V.V., 2016. Preparation of High-Density Fibrillar Collagen Matrices That Mimic

Desmoplastic Tumor Stroma. Current protocols in cell biology 70, 10.19.11-10.19.11.

Artym, V.V., Kindzelskii, A.L., Chen, W.T., Petty, H.R., 2002. Molecular proximity of seprase and the urokinase-type plasminogen activator receptor on malignant melanoma cell membranes: dependence on beta1 integrins and the cytoskeleton. Carcinogenesis 23, 1593-1601. inducer of invadopodia via a specific signaling network. J Cell Biol 208, 331-350.

497 Blake, R.A., Broome, M.A., Liu, X., Wu, J., Gishizky, M., Sun, L., Courtneidge, S.A., 2000. Biol 20, 9018-9027.

Blouw, B., Patel, M., lizuka, S., Abdullah, C., You, W.K., Huang, X., Li, J.L., Diaz, B., Stallcup, of human breast cancer cells in vitro and in vivo. PLoS One 10, e0121003.

Brakebusch, C., Fassler, R., 2005. beta 1 integrin function in vivo: adhesion, migration and more.

504 Cancer Metastasis Rev 24, 403-411.

505 Buschman, M.D., Bromann, P.A., Cejudo-Martin, P., Wen, F., Pass, I., Courtneidge, S.A., 2009.

506 The novel adaptor protein Tks4 (SH3PXD2B) is required for functional podosome formation. Mol 507 Biol Cell 20, 1302-1311.

508 Cejudo-Martin, P., Yuen, A., Vlahovich, N., Lock, P., Courtneidge, S.A., Diaz, B., 2014. Genetic 509 disruption of the sh3pxd2a gene reveals an essential role in mouse development and the 510 existence of a novel isoform of tks5. PLoS One 9, e107674. 
511 Chang, C., Werb, Z., 2001. The many faces of metalloproteases: cell growth, invasion,

512 angiogenesis and metastasis. Trends in cell biology 11, S37-43.

513 Chen, W.T., 1989. Proteolytic activity of specialized surface protrusions formed at rosette contact

514 sites of transformed cells. The Journal of experimental zoology 251, 167-185.

515 Creech, M.K., Wang, J., Nan, X., Gibbs, S.L., 2017. Superresolution Imaging of Clinical Formalin

516 Fixed Paraffin Embedded Breast Cancer with Single Molecule Localization Microscopy. Sci Rep

$517 \quad 7,40766$.

518 Crimaldi, L., Courtneidge, S.A., Gimona, M., 2009. Tks5 recruits AFAP-110, p190RhoGAP, and

519 cortactin for podosome formation. Exp Cell Res 315, 2581-2592.

520 Diaz, B., Shani, G., Pass, I., Anderson, D., Quintavalle, M., Courtneidge, S.A., 2009. Tks5-

521 dependent, nox-mediated generation of reactive oxygen species is necessary for invadopodia

522 formation. Sci Signal 2, ra53.

523 Diaz, B., Yuen, A., lizuka, S., Higashiyama, S., Courtneidge, S.A., 2013. Notch increases the 524 shedding of HB-EGF by ADAM12 to potentiate invadopodia formation in hypoxia. J Cell Biol 201, $525 \quad 279-292$.

526 Eckert, M.A., Lwin, T.M., Chang, A.T., Kim, J., Danis, E., Ohno-Machado, L., Yang, J., 2011.

527 Twist1-induced invadopodia formation promotes tumor metastasis. Cancer Cell 19, 372-386.

528 Gligorijevic, B., Bergman, A., Condeelis, J., 2014. Multiparametric classification links tumor 529 microenvironments with tumor cell phenotype. PLoS biology 12, e1001995.

530 Hanahan, D., Weinberg, R.A., 2011. Hallmarks of cancer: the next generation. Cell 144, 646-674.

531 Hannant, J., Hedley, J.H., Pate, J., Walli, A., Farha Al-Said, S.A., Galindo, M.A., Connolly, B.A., 532 Horrocks, B.R., Houlton, A., Pike, A.R., 2010. Modification of DNA-templated conductive polymer 533 nanowires via click chemistry. Chem Commun (Camb) 46, 5870-5872.

534 Henriet, P., Zhong, Z.D., Brooks, P.C., Weinberg, K.I., DeClerck, Y.A., 2000. Contact with fibrillar 535 collagen inhibits melanoma cell proliferation by up-regulating p27KIP1. Proc Natl Acad Sci U S A $53697,10026-10031$. 
Hoshino, D., Kirkbride, K.C., Costello, K., Clark, E.S., Sinha, S., Grega-Larson, N., Tyska, M.J., Weaver, A.M., 2013. Exosome secretion is enhanced by invadopodia and drives invasive behavior. Cell reports 5, 1159-1168.

Huang, B., Wang, W., Bates, M., Zhuang, X., 2008. Three-dimensional super-resolution imaging by stochastic optical reconstruction microscopy. Science $319,810-813$.

lizuka, S., Abdullah, C., Buschman, M.D., Diaz, B., Courtneidge, S.A., 2016. The role of Tks adaptor proteins in invadopodia formation, growth and metastasis of melanoma. Oncotarget 7 , 78473-78486.

Itoh, Y., 2018. Discoidin domain receptors: Microenvironment sensors that promote cellular migration and invasion. Cell adhesion \& migration 12, 378-385.

Jacob, A., Linklater, E., Bayless, B.A., Lyons, T., Prekeris, R., 2016. The role and regulation of Rab40b-Tks5 complex during invadopodia formation and cancer cell invasion. J Cell Sci 129, 4341-4353.

Juin, A., Di Martino, J., Leitinger, B., Henriet, E., Gary, A.S., Paysan, L., Bomo, J., Baffet, G., Gauthier-Rouviere, C., Rosenbaum, J., Moreau, V., Saltel, F., 2014. Discoidin domain receptor 1 controls linear invadosome formation via a Cdc42-Tuba pathway. J Cell Biol 207, 517-533.

Keely, P.J., 2011. Mechanisms by which the extracellular matrix and integrin signaling act to regulate the switch between tumor suppression and tumor promotion. Journal of mammary gland biology and neoplasia 16, 205-219.

Kelm, J.M., Timmins, N.E., Brown, C.J., Fussenegger, M., Nielsen, L.K., 2003. Method for generation of homogeneous multicellular tumor spheroids applicable to a wide variety of cell types. Biotechnol Bioeng 83, 173-180.

Kim, H.G., Tan, L., Weisberg, E.L., Liu, F., Canning, P., Choi, H.G., Ezell, S.A., Wu, H., Zhao, Z., Wang, J., Mandinova, A., Griffin, J.D., Bullock, A.N., Liu, Q., Lee, S.W., Gray, N.S., 2013. Discovery of a potent and selective DDR1 receptor tyrosine kinase inhibitor. ACS Chem Biol 8, 2145-2150. 
563

564

565

566

567

568

569

570

571

572

573

574

575

576

577

578

579

580

581

582

583

584

585

586

587

Kohler, G., Milstein, C., 1975. Continuous cultures of fused cells secreting antibody of predefined specificity. Nature 256, 495-497.

Laird, A.D., Li, G., Moss, K.G., Blake, R.A., Broome, M.A., Cherrington, J.M., Mendel, D.B., 2003.

Src family kinase activity is required for signal tranducer and activator of transcription 3 and focal adhesion kinase phosphorylation and vascular endothelial growth factor signaling in vivo and for anchorage-dependent and -independent growth of human tumor cells. Mol Cancer Ther 2, 461469.

Leitinger, B., Hohenester, E., 2007. Mammalian collagen receptors. Matrix biology : journal of the International Society for Matrix Biology 26, 146-155.

Leong, H.S., Robertson, A.E., Stoletov, K., Leith, S.J., Chin, C.A., Chien, A.E., Hague, M.N., Ablack, A., Carmine-Simmen, K., McPherson, V.A., Postenka, C.O., Turley, E.A., Courtneidge, S.A., Chambers, A.F., Lewis, J.D., 2014. Invadopodia are required for cancer cell extravasation and are a therapeutic target for metastasis. Cell reports 8, 1558-1570.

Li, C.M., Chen, G., Dayton, T.L., Kim-Kiselak, C., Hoersch, S., Whittaker, C.A., Bronson, R.T., Beer, D.G., Winslow, M.M., Jacks, T., 2013. Differential Tks5 isoform expression contributes to metastatic invasion of lung adenocarcinoma. Genes \& development 27, 1557-1567.

Linder, S., 2007. The matrix corroded: podosomes and invadopodia in extracellular matrix degradation. Trends in cell biology 17, 107-117.

Linder, S., Wiesner, C., Himmel, M., 2011. Degrading devices: invadosomes in proteolytic cell invasion. Annual review of cell and developmental biology 27, 185-211.

Lock, P., Abram, C.L., Gibson, T., Courtneidge, S.A., 1998. A new method for isolating tyrosine kinase substrates used to identify fish, an SH3 and PX domain-containing protein, and Src substrate. EMBO J 17, 4346-4357.

Lu, P., Weaver, V.M., Werb, Z., 2012. The extracellular matrix: a dynamic niche in cancer progression. J Cell Biol 196, 395-406. 
588

589

590

591

592

593

594

595

596

597

598

599

600

601

602

603

604

605

606

607

608

609

610

611

612

613

Lukinavicius, G., Umezawa, K., Olivier, N., Honigmann, A., Yang, G., Plass, T., Mueller, V., Reymond, L., Correa, I.R., Jr., Luo, Z.G., Schultz, C., Lemke, E.A., Heppenstall, P., Eggeling, C., Manley, S., Johnsson, K., 2013. A near-infrared fluorophore for live-cell super-resolution microscopy of cellular proteins. Nat Chem 5, 132-139.

Luxenburg, C., Geblinger, D., Klein, E., Anderson, K., Hanein, D., Geiger, B., Addadi, L., 2007.

The architecture of the adhesive apparatus of cultured osteoclasts: from podosome formation to sealing zone assembly. PLoS One 2, e179.

Maller, O., Hansen, K.C., Lyons, T.R., Acerbi, I., Weaver, V.M., Prekeris, R., Tan, A.C., Schedin, P., 2013. Collagen architecture in pregnancy-induced protection from breast cancer. J Cell Sci $126,4108-4110$.

Monsky, W.L., Lin, C.Y., Aoyama, A., Kelly, T., Akiyama, S.K., Mueller, S.C., Chen, W.T., 1994. A potential marker protease of invasiveness, seprase, is localized on invadopodia of human malignant melanoma cells. Cancer Res 54, 5702-5710.

Murphy, D.A., Courtneidge, S.A., 2011. The 'ins' and 'outs' of podosomes and invadopodia: characteristics, formation and function. Nat Rev Mol Cell Biol 12, 413-426.

Murphy, D.A., Diaz, B., Bromann, P.A., Tsai, J.H., Kawakami, Y., Maurer, J., Stewart, R.A., Izpisua-Belmonte, J.C., Courtneidge, S.A., 2011. A Src-Tks5 pathway is required for neural crest cell migration during embryonic development. PLoS One 6, e22499.

Oikawa, T., Itoh, T., Takenawa, T., 2008. Sequential signals toward podosome formation in NIHsrc cells. J Cell Biol 182, 157-169.

Ovesny, M., Krizek, P., Borkovec, J., Svindrych, Z., Hagen, G.M., 2014. ThunderSTORM: a comprehensive ImageJ plug-in for PALM and STORM data analysis and super-resolution imaging. Bioinformatics 30, 2389-2390.

Parekh, A., Ruppender, N.S., Branch, K.M., Sewell-Loftin, M.K., Lin, J., Boyer, P.D., Candiello, J.E., Merryman, W.D., Guelcher, S.A., Weaver, A.M., 2011. Sensing and modulation of invadopodia across a wide range of rigidities. Biophysical journal 100, 573-582. 
Pickup, M.W., Mouw, J.K., Weaver, V.M., 2014. The extracellular matrix modulates the hallmarks of cancer. EMBO reports 15, 1243-1253.

616 Quintavalle, M., Elia, L., Condorelli, G., Courtneidge, S.A., 2010. MicroRNA control of podosome 617 formation in vascular smooth muscle cells in vivo and in vitro. J Cell Biol 189, 13-22.

618 Rammal, H., Saby, C., Magnien, K., Van-Gulick, L., Garnotel, R., Buache, E., El Btaouri, H., 619 Jeannesson, P., Morjani, H., 2016. Discoidin Domain Receptors: Potential Actors and Targets in 620 Cancer. Front Pharmacol 7, 55.

621 Ren, T., Zhang, W., Liu, X., Zhao, H., Zhang, J., Zhang, J., Li, X., Zhang, Y., Bu, X., Shi, M., Yao, L., Su, J., 2014. Discoidin domain receptor 2 (DDR2) promotes breast cancer cell metastasis and 623 the mechanism implicates epithelial-mesenchymal transition programme under hypoxia. The Journal of pathology 234, 526-537.

625 Rick, J.W., Chandra, A., Dalle Ore, C., Nguyen, A.T., Yagnik, G., Aghi, M.K., 2019. Fibronectin in 626 malignancy: Cancer-specific alterations, protumoral effects, and therapeutic implications. Semin

627 Oncol 46, 284-290.

628 Rufer, A.C., Rumpf, J., von Holleben, M., Beer, S., Rittinger, K., Groemping, Y., 2009. Isoform629 selective interaction of the adaptor protein Tks5/FISH with Sos1 and dynamins. J Mol Biol 390, $630 \quad 939-950$.

631 Saghatelian, A., Jessani, N., Joseph, A., Humphrey, M., Cravatt, B.F., 2004. Activity-based 632 probes for the proteomic profiling of metalloproteases. Proc Natl Acad Sci U S A 101, 1000063310005.

634 Saini, P., Courtneidge, S.A., 2018. Tks adaptor proteins at a glance. J Cell Sci 131.

635 Scandolera, A., Odoul, L., Salesse, S., Guillot, A., Blaise, S., Kawecki, C., Maurice, P., El Btaouri, 636 H., Romier-Crouzet, B., Martiny, L., Debelle, L., Duca, L., 2016. The Elastin Receptor Complex: 637 A Unique Matricellular Receptor with High Anti-tumoral Potential. Front Pharmacol 7, 32. 
Schedin, P., Keely, P.J., 2011. Mammary gland ECM remodeling, stiffness, and mechanosignaling in normal development and tumor progression. Cold Spring Harb Perspect Biol 3, a003228.

Schnitzbauer, J., Strauss, M.T., Schlichthaerle, T., Schueder, F., Jungmann, R., 2017. Superresolution microscopy with DNA-PAINT. Nat Protoc 12, 1198-1228.

Schoumacher, M., Goldman, R.D., Louvard, D., Vignjevic, D.M., 2010. Actin, microtubules, and vimentin intermediate filaments cooperate for elongation of invadopodia. J Cell Biol 189, 541-556. Seals, D.F., Azucena, E.F., Jr., Pass, I., Tesfay, L., Gordon, R., Woodrow, M., Resau, J.H., Courtneidge, S.A., 2005. The adaptor protein Tks5/Fish is required for podosome formation and function, and for the protease-driven invasion of cancer cells. Cancer Cell 7, 155-165.

Seals, D.F., Courtneidge, S.A., 2003. The ADAMs family of metalloproteases: multidomain proteins with multiple functions. Genes \& development 17, 7-30.

Sharma, V.P., Eddy, R., Entenberg, D., Kai, M., Gertler, F.B., Condeelis, J., 2013. Tks5 and SHIP2 regulate invadopodium maturation, but not initiation, in breast carcinoma cells. Current biology : CB 23, 2079-2089.

Smith, R., Devlin, K., Kilburn, D., Gross, S., Sudar, D., Bucher, E., Nederlof, M., Dane, M., Gray, J.W., Heiser, L., Korkola, J.E., 2019. Using Microarrays to Interrogate Microenvironmental Impact on Cellular Phenotypes in Cancer. J Vis Exp.

Stylli, S.S., Stacey, T.T., Verhagen, A.M., Xu, S.S., Pass, I., Courtneidge, S.A., Lock, P., 2009. Nck adaptor proteins link Tks5 to invadopodia actin regulation and ECM degradation. J Cell Sci $122,2727-2740$.

Tarone, G., Cirillo, D., Giancotti, F.G., Comoglio, P.M., Marchisio, P.C., 1985. Rous sarcoma virus-transformed fibroblasts adhere primarily at discrete protrusions of the ventral membrane called podosomes. Exp Cell Res 159, 141-157.

Tu, C., Ortega-Cava, C.F., Chen, G., Fernandes, N.D., Cavallo-Medved, D., Sloane, B.F., Band, V., Band, H., 2008. Lysosomal cathepsin B participates in the podosome-mediated extracellular 
664

665

666

667

668

669

670

671

672

673

674

675

676

677

678

679

680

681

682

683

684

685

686

matrix degradation and invasion via secreted lysosomes in v-Src fibroblasts. Cancer Res 68, 9147-9156.

Valiathan, R.R., Marco, M., Leitinger, B., Kleer, C.G., Fridman, R., 2012. Discoidin domain receptor tyrosine kinases: new players in cancer progression. Cancer Metastasis Rev 31, 295321.

van de Linde, S., Loschberger, A., Klein, T., Heidbreder, M., Wolter, S., Heilemann, M., Sauer, M., 2011. Direct stochastic optical reconstruction microscopy with standard fluorescent probes. Nat Protoc 6, 991-1009.

Vindin, H., Mithieux, S.M., Weiss, A.S., 2019. Elastin architecture. Matrix biology : journal of the International Society for Matrix Biology 84, 4-16.

Watson, S.S., Dane, M., Chin, K., Tatarova, Z., Liu, M., Liby, T., Thompson, W., Smith, R., Nederlof, M., Bucher, E., Kilburn, D., Whitman, M., Sudar, D., Mills, G.B., Heiser, L.M., Jonas, O., Gray, J.W., Korkola, J.E., 2018. Microenvironment-Mediated Mechanisms of Resistance to HER2 Inhibitors Differ between HER2+ Breast Cancer Subtypes. Cell Syst 6, 329-342 e326.

Weaver, A.M., 2008a. Cortactin in tumor invasiveness. Cancer Lett 265, 157-166.

Weaver, A.M., 2008b. Invadopodia. Current biology : CB 18, R362-364.

Xiao, J., Broz, P., Puri, A.W., Deu, E., Morell, M., Monack, D.M., Bogyo, M., 2013. A coupled protein and probe engineering approach for selective inhibition and activity-based probe labeling of the caspases. J Am Chem Soc 135, 9130-9138.

Zhang, K., Corsa, C.A., Ponik, S.M., Prior, J.L., Piwnica-Worms, D., Eliceiri, K.W., Keely, P.J., Longmore, G.D., 2013. The collagen receptor discoidin domain receptor 2 stabilizes SNAIL1 to facilitate breast cancer metastasis. Nat Cell Biol 15, 677-687. 


\section{Figure 1. Tks5 antibodies against PX domain (F4) and linker region (G6).}

A Schematic view of Tks5 isoforms and antibody epitope regions. B Antibody specificity analyzed by immunoblotting on extracts from 293T cells transiently expressing full-length of Tks5a (Tks5),

Tks5a with PX domain deletion ( $\triangle \mathrm{PX}$ ) or full-length of Tks4 (Tks4). C Tks5 protein levels analyzed by immunoblotting on human breast cancer cell lines. Asterisks show predicted size of Tks5a $\left({ }^{*}\right)$ and Tks5 $\beta /$ short $\left({ }^{* *}\right)$. Tubulin is shown as a loading control. D and E Validation of antibodies by immunofluorescence. (D) All Tks5 isoforms were stained by G6 in MDA-MB-231 cells with shRNA-scrambled (Ctrl), shRNA-Tks5 (D6) or shRNA-Tks5 (D7). Invadopodia were visualized by Tks5 (G6, green) and actin (phalloidin, red). (E) Tks5a was stained by F4 in Src-transformed NIH3T3 cells with Tks5aGFP overexpression. Magnified areas (1 and 2, orange square in top) were shown. Arrows show Tks5 accumulation at invadopodia. Arrowheads show Tks5a signals and $2 \mu \mathrm{m}$ (E right, $\mathrm{F}$ bottom).

\section{Figure 2. Crosstalk between invadopodia and the extracellular matrix.}

A Growth of cells as indicated in the figure in 3D native type I collagen (3D native COLI) and in 3D matrigel (3D matrigel). Red line shows the cell number when they were embedded in matrix. 
712

713

714

715

716

717

718

719

720

721

722

723

724

725

726

727

728

729

730

731

732

733

734

735

736

cells as indicated in the figure on high-dense type I collagen (HDFC) and in 3D native type I collagen (3D native COLI). Fold change in cell number in MDA-MB-231 cells with shRNAscrambled (Ctrl), shRNA-Tks5 (D6), shRNA-Tks5-D6 with rescued expression of Tks5aGFP (D6R) or shRNA-DDR1/2 (DDR1/2). E 3D growth/invasion in a hanging droplet spheroid assay with DDR inhibitor, DDR-IN-1. Representative images of spheroids in type I collagen stained by phalloidin (left) and spheroid size measured by actin intensity (right). Scale bars, $5 \mu \mathrm{m}(\mathrm{C})$ and $500 \mu \mathrm{m}(\mathrm{E}) . \quad P>0.05$ unless other specified; ${ }^{*}, P<0.05 ;{ }^{* *}, P<0.01 ;{ }^{* * *}, P<0.001$.

Figure 3. Invadopodia formation assay on microenvironmental microarray (MEMA).

A Overall view from one of the MEMA assays with MDA-MB-231 cells. Invadopodia were visualized by actin (phalloidin) and Tks5aGFP. B Representative zoom-in images from each spot as indicated in the figure (type I collagen: COLI, fibronectin: FN, laminin: LAM and tropoelastin). Magnified areas (orange square at top) shown at bottom. Hoechst staining reveals nuclei of cells in the images. Scale bars, $500 \mu \mathrm{m}(\mathrm{A})$ and $10 \mu \mathrm{m}(\mathrm{B})$.

\section{Figure 4. Fine structures of invadopodia in 3D type I collagen.}

A Invadopodia were visualized in a 3D type I collagen hanging droplet spheroids. Representative images of MDA-MB-231 spheroids stained by phalloidin (red) and Tks5aGFP (green). Magnified areas (orange square in left) were shown in middle. Hoechst staining reveals nuclei of cells in the images. Magnified orthogonal view (orange square in middle) shown at right. B Invadopodia in MDA-MB-231 cells with Tks5aGFP were visualized on high-dense fibrillar collagen (HDFC). Representative images of invadopodia stained by phalloidin (red), Tks5aGFP (green) and HDFC (gray). Magnified orthogonal view (orange square in left and middle) shown in the middle and atright. 3D reconstruction images were processed by using Imaris software (3D signal or spots, bottom). C Invadopodia on HDFC were visualized by phalloidin (red) and Tks5aGFP (green). 
Hoechst to denote nuclei of cells in the images. Magnified orthogonal view (orange square in left) were shown in middle. Digital zoom-in image from single z-stack plane in middle (orange square) was shown in right. D 3D super-resolution microscopy (SRM) image of invadopodia on HDFC. Sample was prepared at same time as in C. E Comparison of invadopodia on HDFC between confocal microscopy and SRM. Representative images and structural information as indicated in the figure. Scale bars, $100 \mu \mathrm{m}$ (A left), $10 \mu \mathrm{m}$ (A middle), $5 \mu \mathrm{m}$ (B top left, $\mathrm{C}$ left), $2 \mu \mathrm{m}$ (A right, B top middle) and $1 \mu \mathrm{m}$ (B top right, B bottom three, $\mathrm{C}$ right three).

\section{Figure 5. Localization of invadopodia components on HDFC.}

A Invadopodia in MDA-MB-231 cells with Tks5aGFP and Tks5a-mCherry were visualized on HDFC. Representative images of invadopodia stained by phalloidin (gray), Tks5a-mCherry (red) and Tks5aGFP (green). Magnified orthogonal view (orange square in top) shown at bottom. Digital zoom-in side-view image from single invadopodia in bottom (orange square) shown at right. Dot-line shows the area of cell membrane. B Invadopodia side-view images in Tks5amCherry overexpressing MDA-MB-231 cells with cortactin-GFP, N-WASP-GFP or fascin-GFP on HDFC. C Schematic view of invadopodia with localization of invadopodia-related proteins in 3D. Scale bars, $5 \mu \mathrm{m}$ (A top) and $3 \mu \mathrm{m}$ (A bottom).

\section{Figure 6. Localization of protease activity at invadopodia on HDFC.}

A MMP activity at Invadopodia in MDA-MB-231 cells with Tks5aGFP were visualized on HDFC. Representative images of invadopodia stained by phalloidin (red), Tks5aGFP (green) and MMP activity (gray, MMP-ABP). Magnified orthogonal view (orange square in left and middle) were shown in middle and right. 3D reconstruction images were processed by using Imaris software (3D signal or spots) and shown in bottom. B Cathepsin activity at invadopodia in MDA-MB-231 cells with Tks5aGFP was visualized on HDFC. Representative images of invadopodia stained by 
762

763

764

765

766

767

768

769

770

771

772

773

774

775

776

777

778

779

780

phalloidin (red), Tks5a (green, F4 antibody) and cathepsin activity (gray, CTS-ABP). Magnified orthogonal view (orange square in left and middle) shown in middle and at right. 3D reconstruction images were processed by using Imaris software (3D signal or spots) and shown at bottom. Scale bars, $5 \mu \mathrm{m}$ (A left, $C$ left, D), $2 \mu \mathrm{m}$ (A right, $C$ right) and $1 \mu \mathrm{m}(B)$.

\section{Figure 7. Role of protease activities in 3D invadopodia.}

A 3D growth/invasion in a hanging droplet spheroid assay in MDA-MB-231 cells with inhibitors, GM6001 or CA074. Representative brightfield images of spheroids in type I collagen (top) with spheroid size measured by actin intensity (bottom). B Invadopodia in MDA-MB-231 cells with Tks5aGFP were visualized on high-dense fibrillar collagen (HDFC). The cells were treated with DMSO, SU11333 $(1 \mu \mathrm{M})$, GM6001 $(10 \mu \mathrm{M})$ or CA074 $(10 \mu \mathrm{M})$. Representative images of invadopodia stained by phalloidin (red), Tks5aGFP (green) and HDFC (gray). Magnified orthogonal view (orange square) shown in left two panels. C Images from B were processed for $3 \mathrm{D}$ reconstruction (3D spots) using Imaris software. Length (z-depth) and intensity of actin or Tks5aGFP (from three representative invadopodia) was analyzed in each condition (C, right graphs). Red dotted-line shows depth of actin intensity 10 in each condition. Green dotted-line shows maximum intensity of Tks $5 \alpha$ GFP in DMSO. D Individual invadopodia length was measured using Imaris software. Scale bars, $5 \mu \mathrm{m}$ (B left, $C$ ) and $1 \mu \mathrm{m}$ (B right). $P>0.05$ unless other specified; * $P<0.001$. 
bioRxiv preprint doi: https://doi.org/10.1101/2020.02.26.966762; this version posted February 27, 2020. The copyright holder for this preprint (which was not certified by peer review) is the author/funder, who has granted bioRxiv a license to display the preprint in perpetuity. It is magigure 1

A

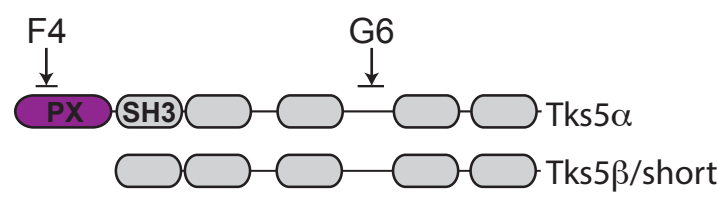

B

G6

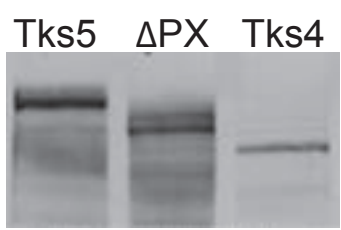

F4

\section{Tks5 $\quad \Delta \mathrm{PX} \quad$ Tks4}

C

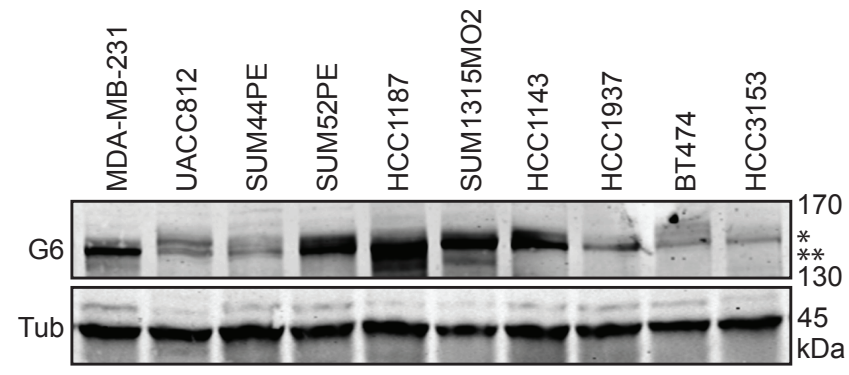

D

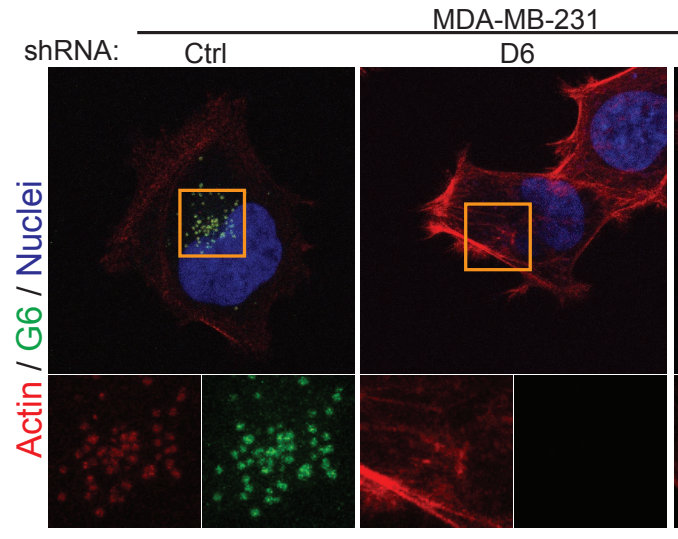

E

MDA-MB-231

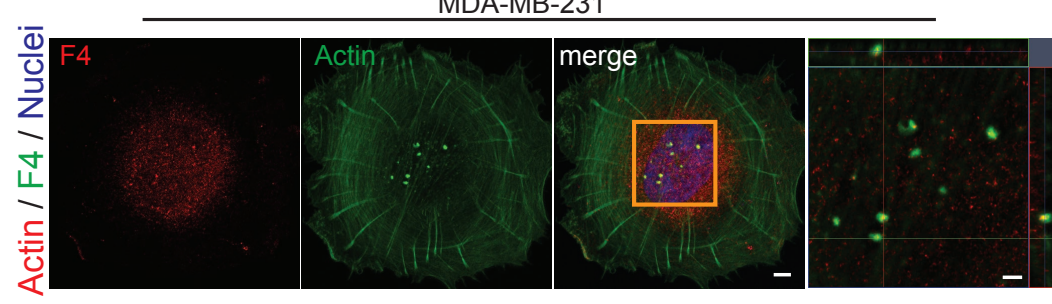

F

F4 / Tks5aGFP / Tub / Nuclei
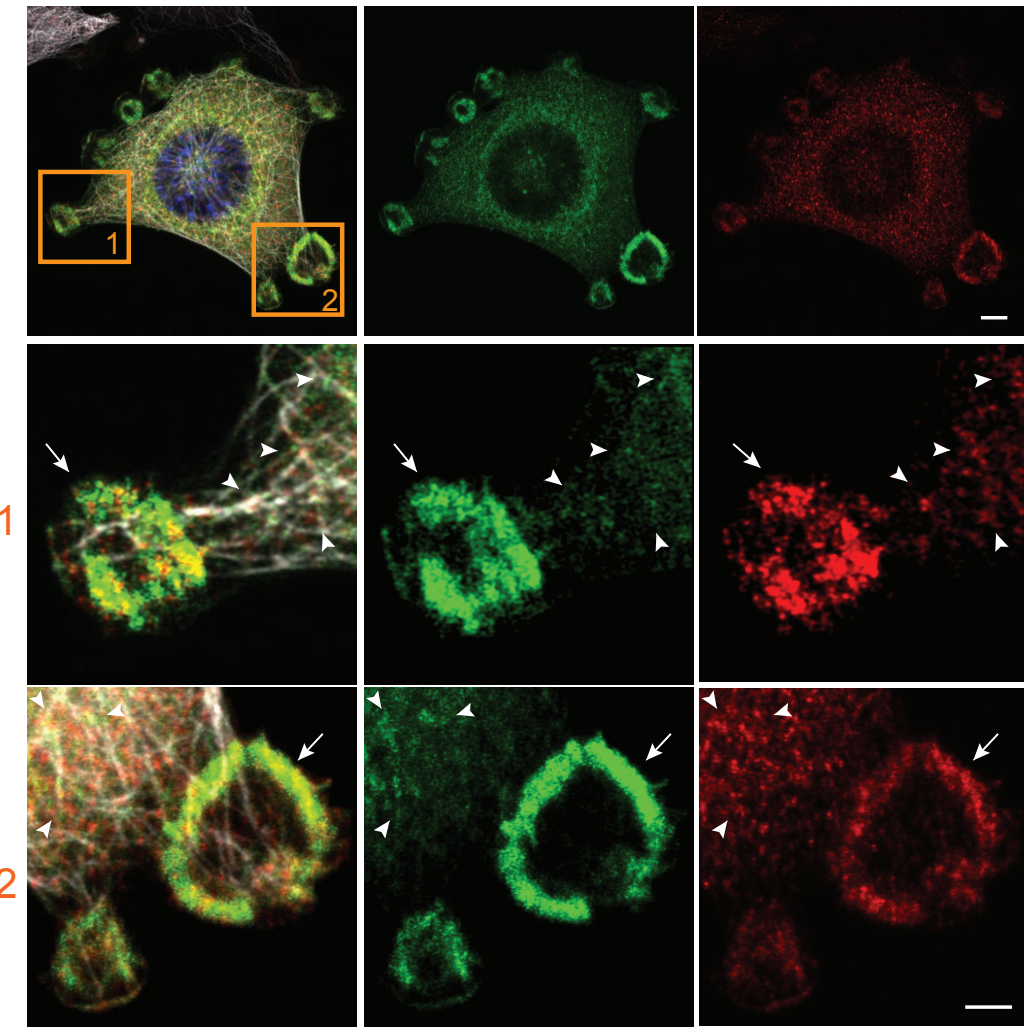
bioRxiv preprint doi: https://doi.org/10.1101/2020.02.26.966762; this version posted February 27, 2020. The copyright holder for this preprint

(which was not certified by peer review) is the author/funder, who has granted bioRxiv a license to display the preprint in perpetuity. It is mapte 9 gure 2

A

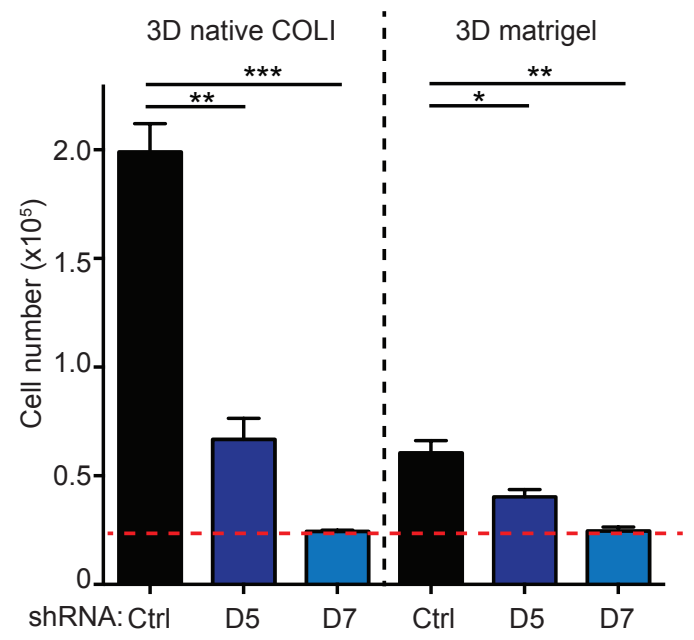

C

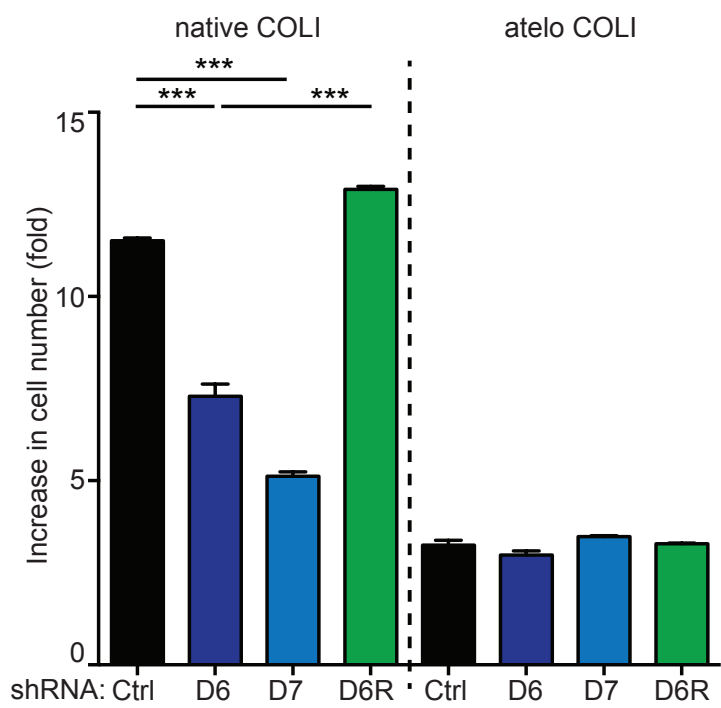

B

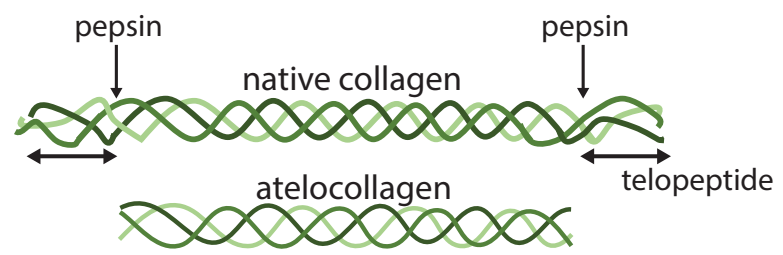

$\mathrm{D}$
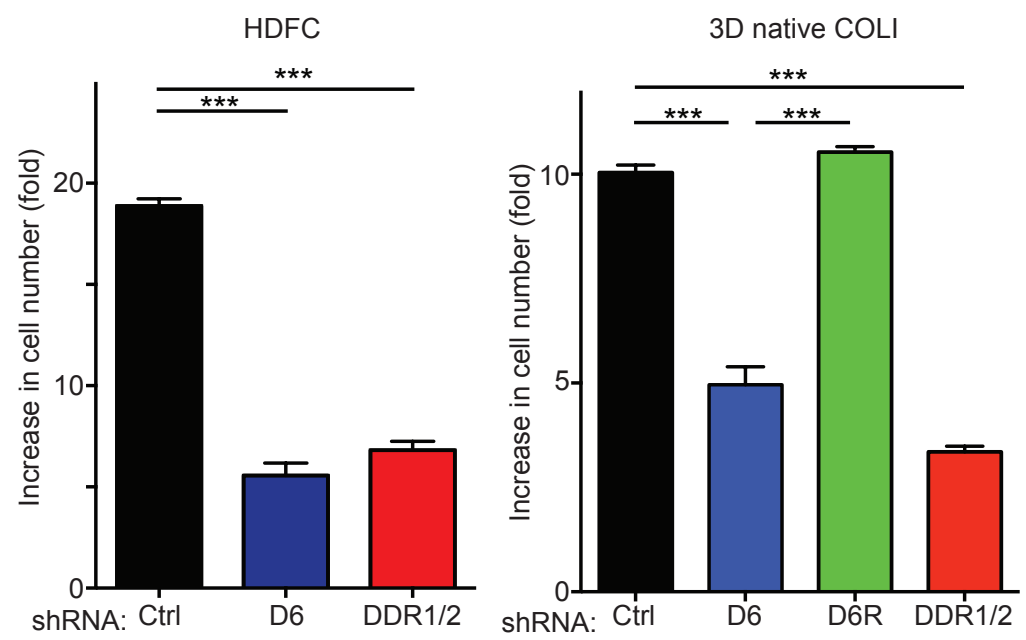
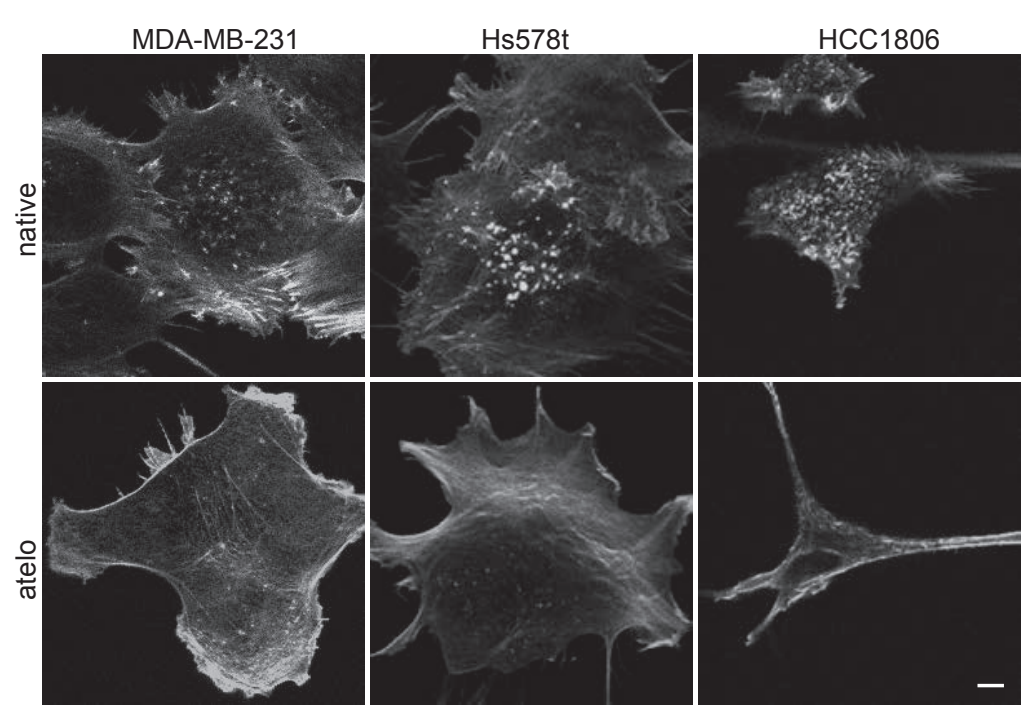

$\mathrm{E}$
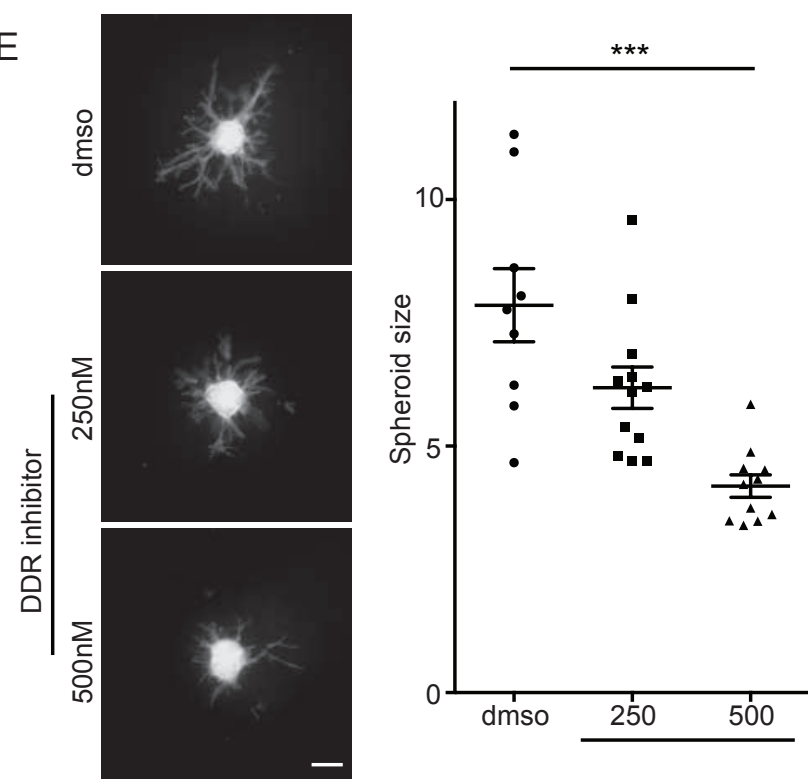
bioRxiv preprint doi: https://doi.org/10.1101/2020.02.26.966762; this version posted February 27, 2020. The copyright holder for this preprint (which was not certified by peer review) is the author/funder, who has granted bioRxiv a license to display the preprint in perpetuity. It is maqge 3

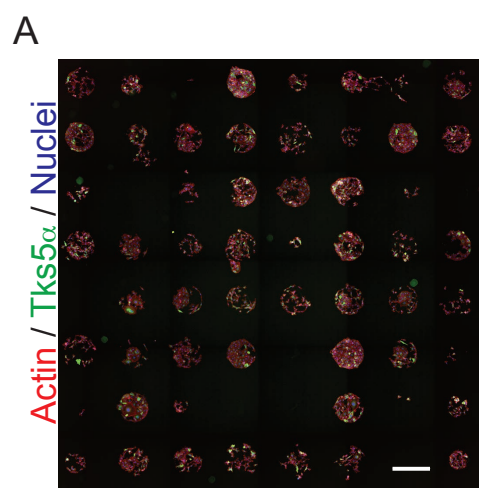

B
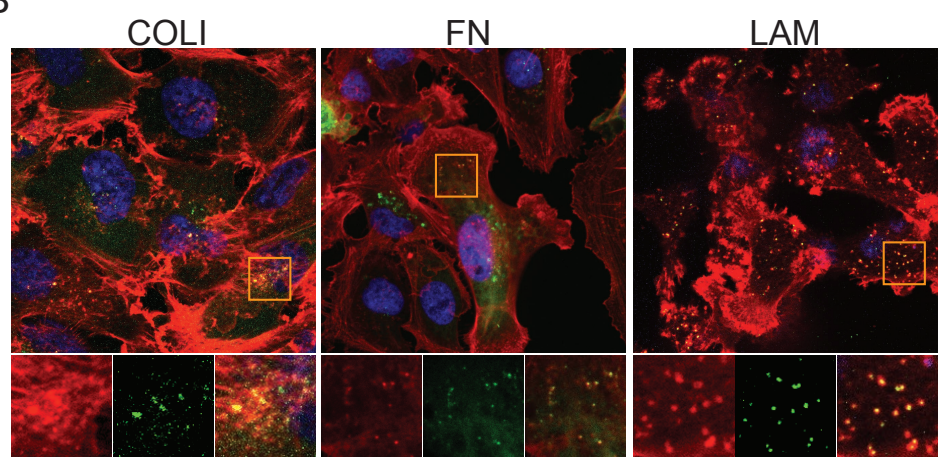

Tropoelastin (ELN)

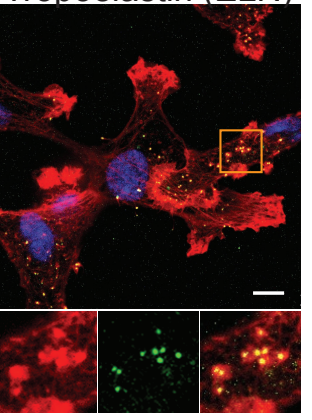


bioRxiv preprint doi: https://doi.org/10.1101/2020.02.26.966762; this version posted February 27, 2020. The copyright holder for this preprint

A (which was not certified by peer review) is the author/funder, who has granted bioRxiv a license to display the preprint in perpetuity. It is maglg
available under aCC-BY-NC-ND 4.0 International license.
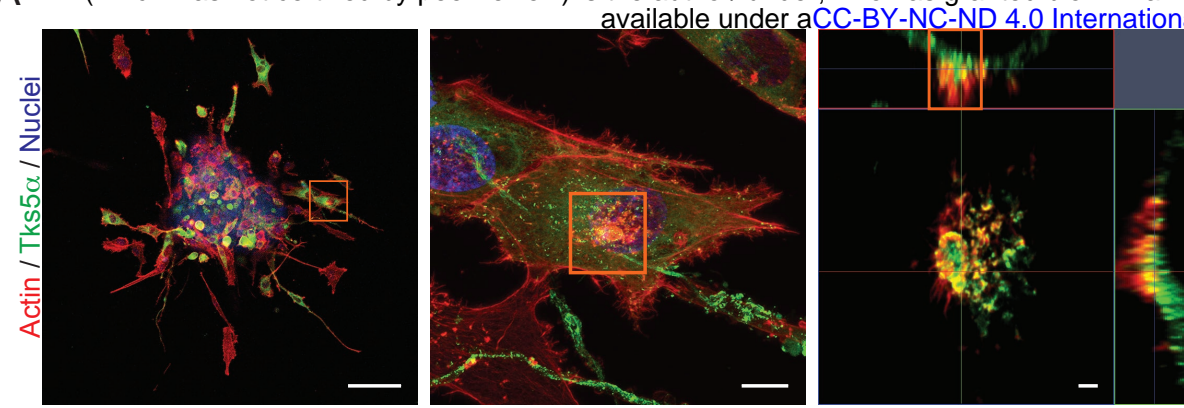

B
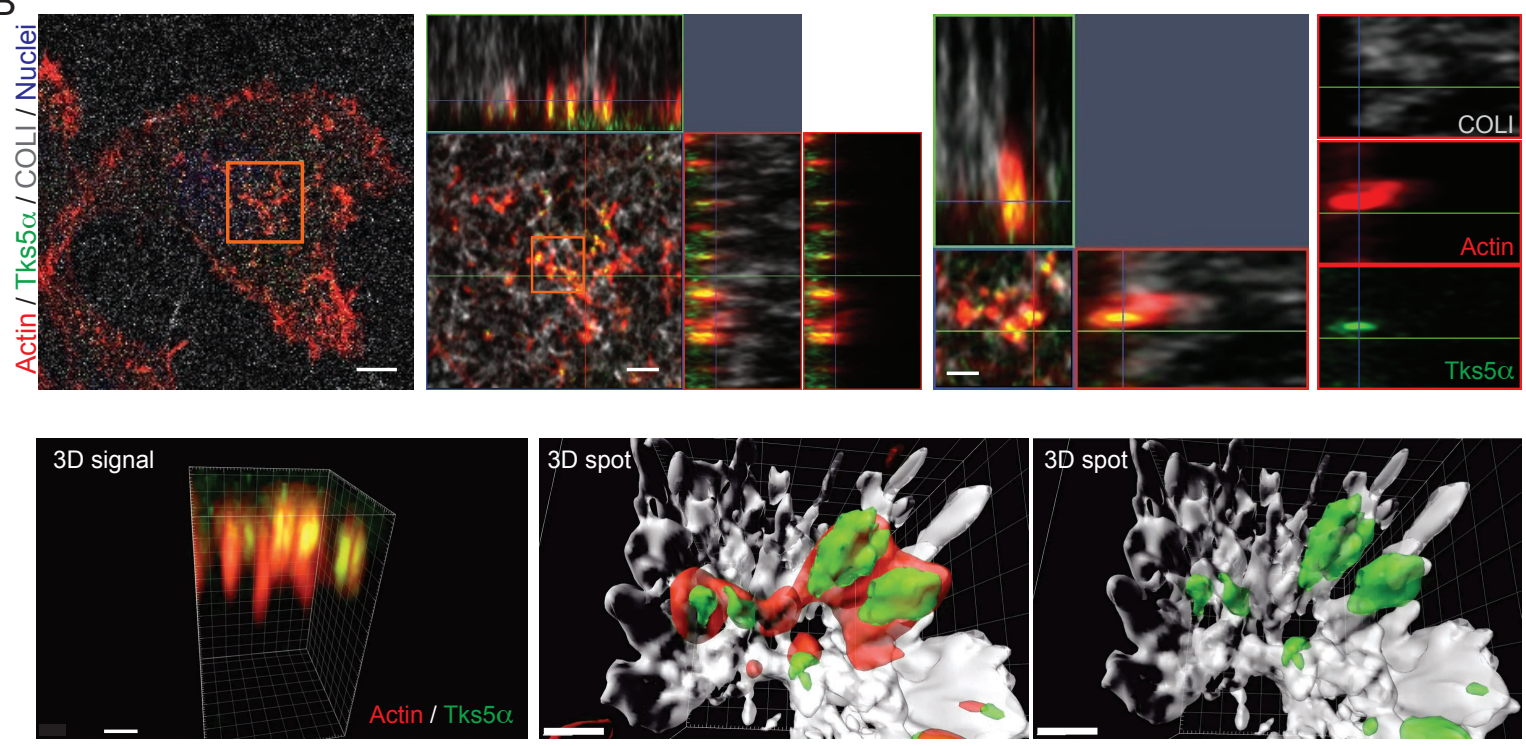

C
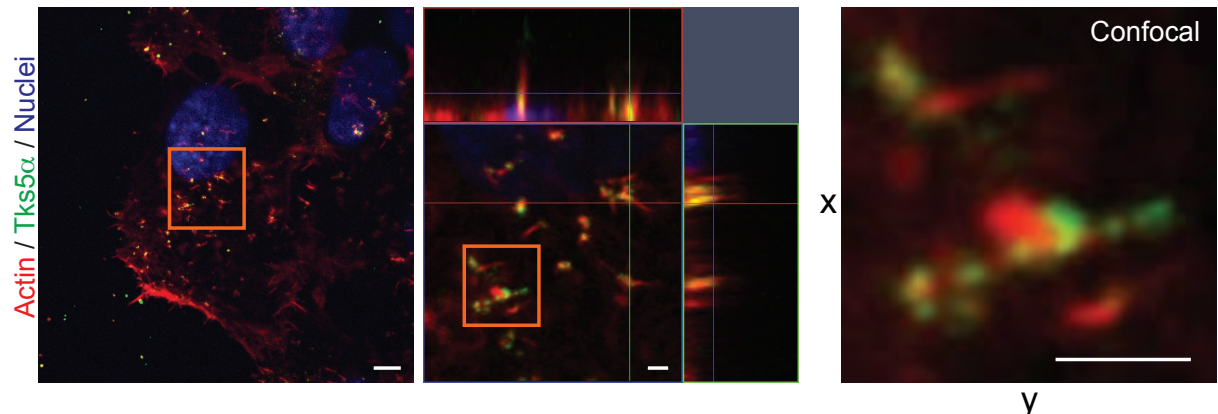

D

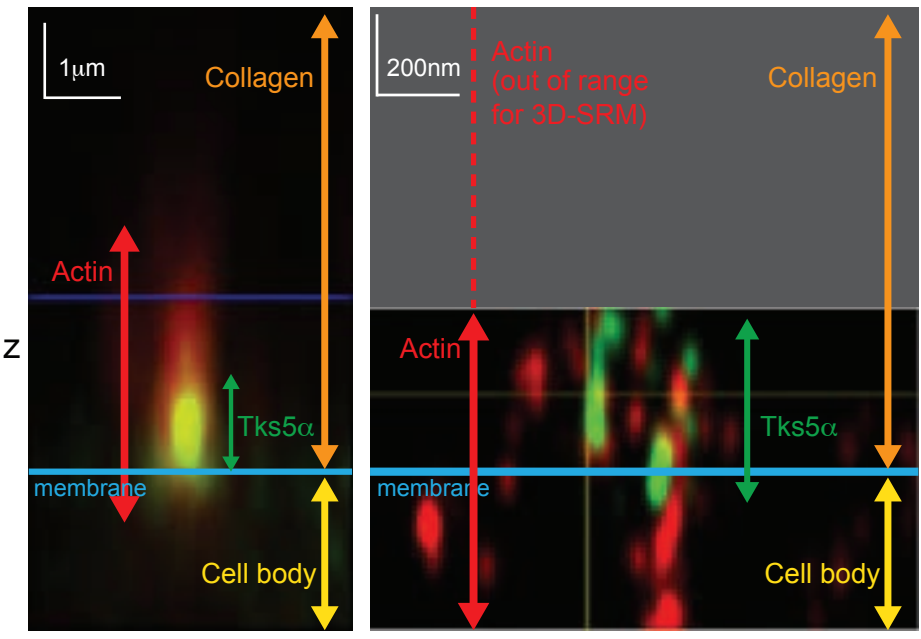


bioRxiv preprint doi: https://doi.org/10.1101/2020.02.26.966762; this version posted February 27, 2020. The copyright holder for this preprint (which was not certified by peer review) is the author/funder, who has granted bioRxiv a license to display the preprint in perpetuity. It is maglgure 5
available under aCC-BY-NC-ND 4.0 International license.

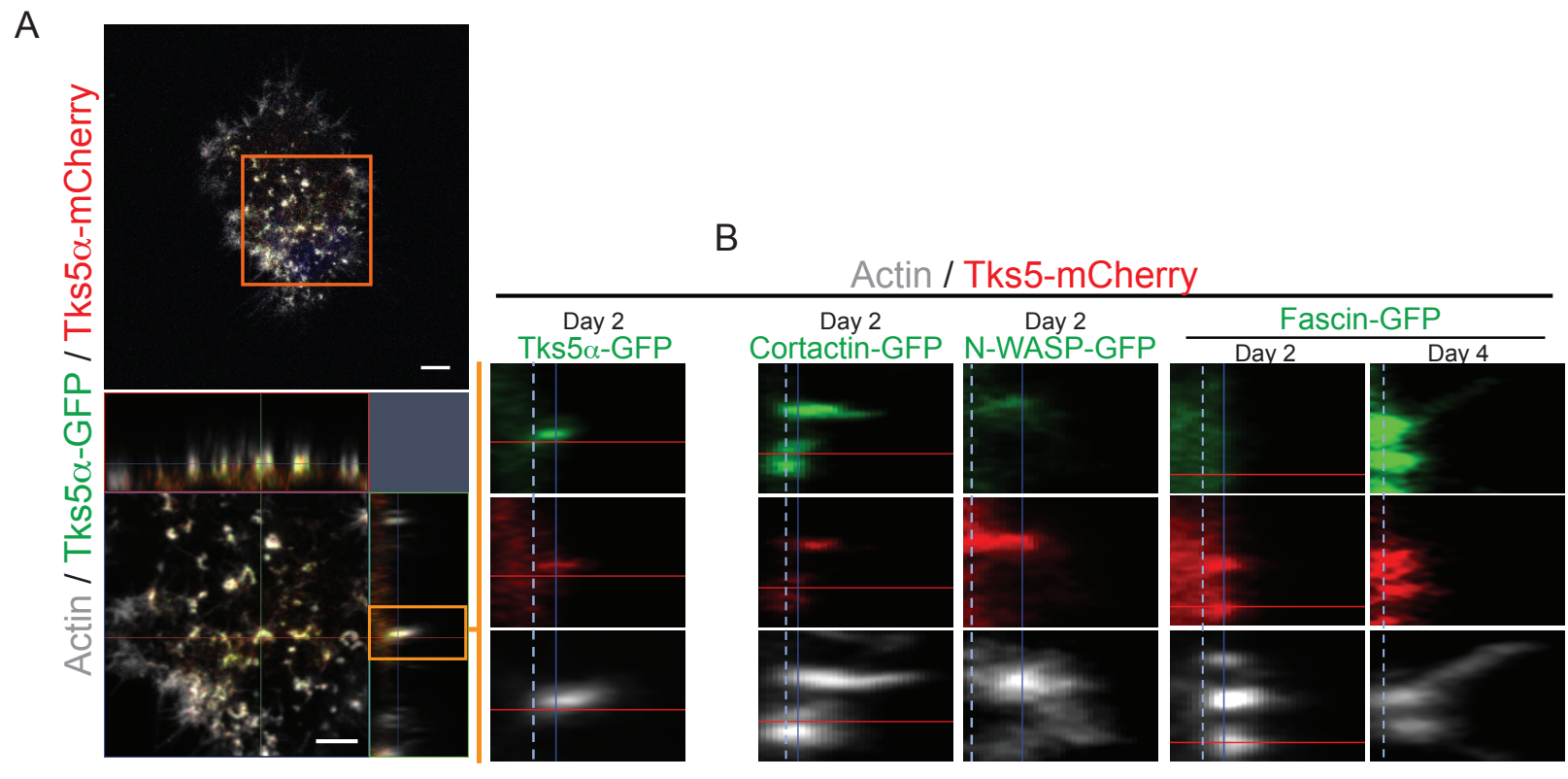

C

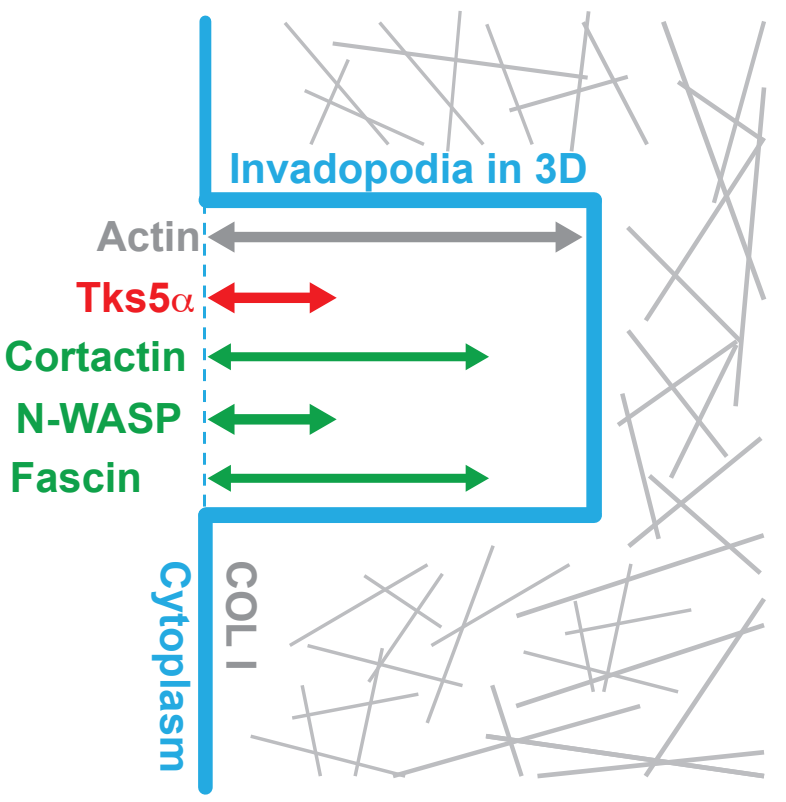


bioRxiv preprint doi: https://doi.org/10.1101/2020.02.26.966762; this version posted February 27, 2020. The copyright holder for this preprint

(which was not certified by peer review) is the author/funder, who has granted bioRxiv a license to display the preprint in perpetuity. It is maqge 6 are 6

A

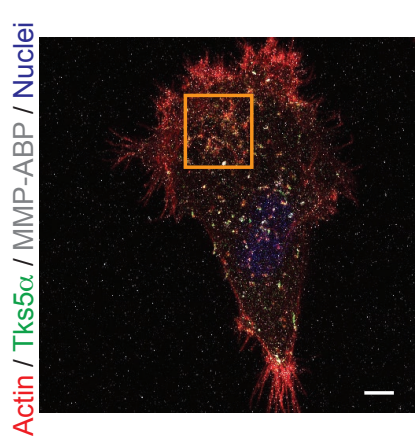

B

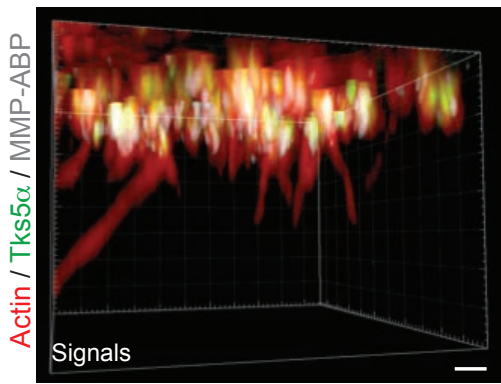

Actin / Tks $5 \alpha$ / MMP-ABP

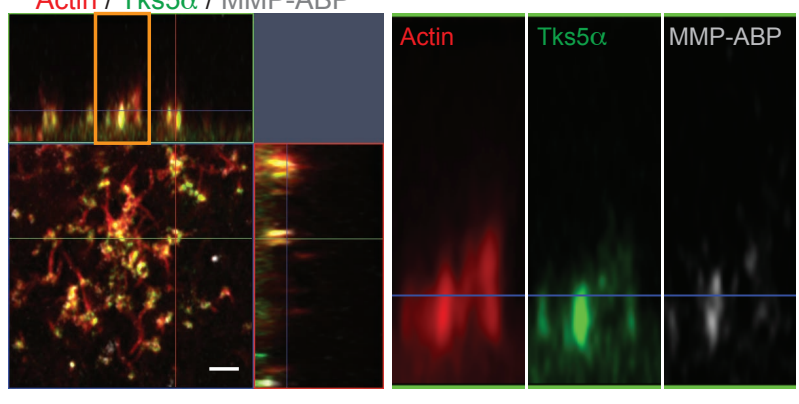

C

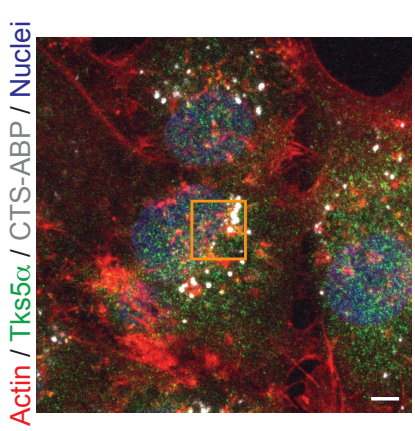

Actin / Tks5 $\alpha$ / CTS-ABP
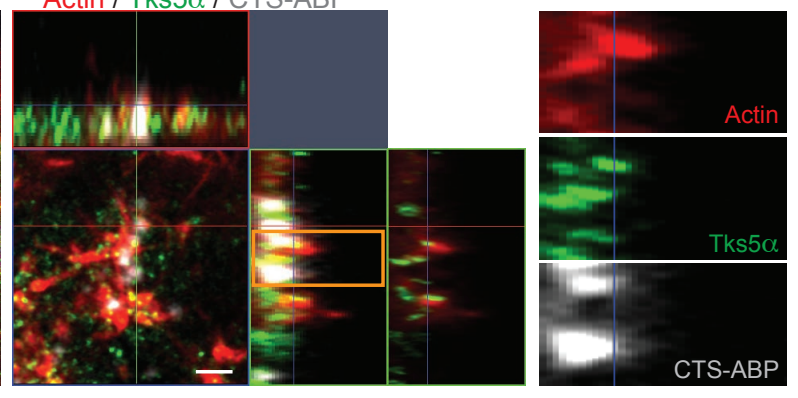

D
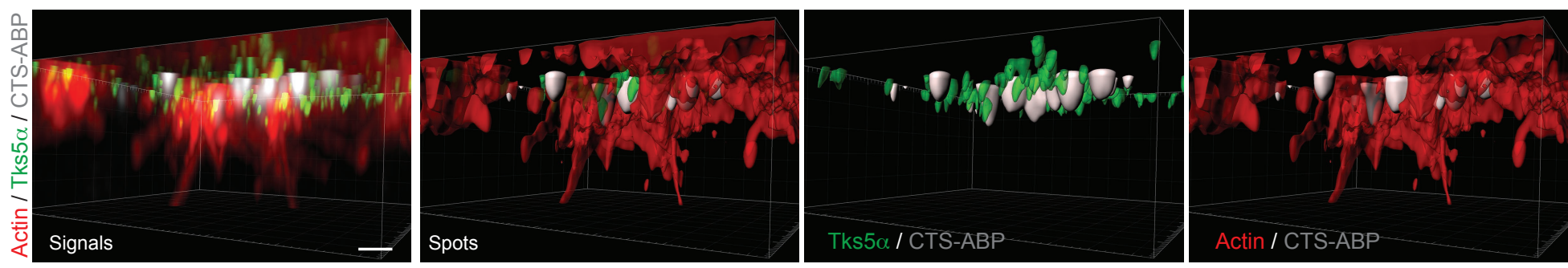
bioRxiv preprint doi: https://doi.org/10.1101/2020.02.26.966762; this version posted February 27, 2020. The copyright holder for this preprint

(which was not certified by peer review) is the author/funder, who has granted bioRxiv a license to display the preprint in perpetuity. It is midegure 7

A
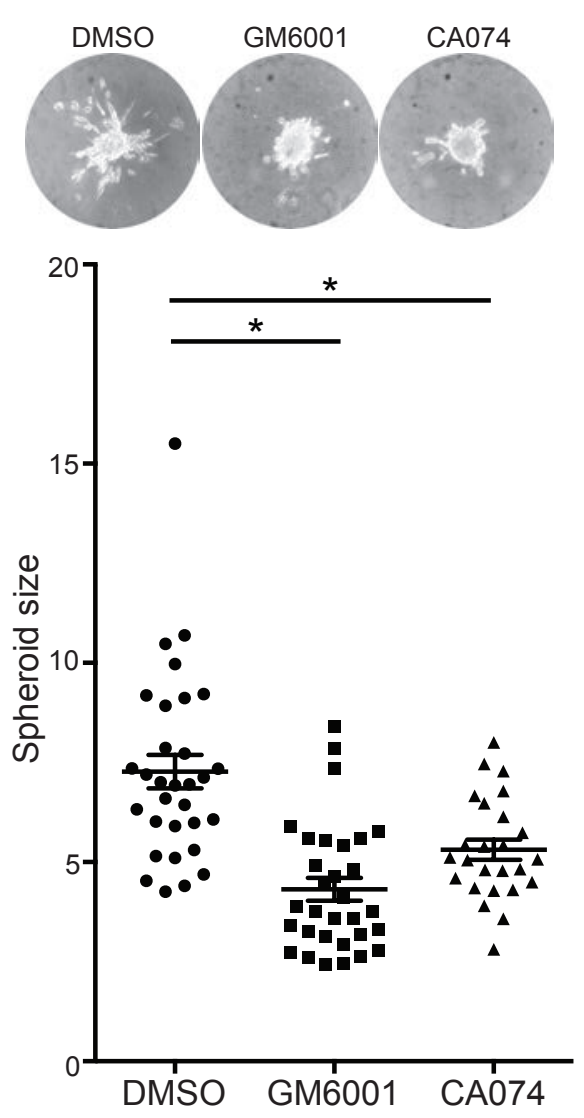

B
Actin / Tks $5 \alpha$ / COLI / Nuclei

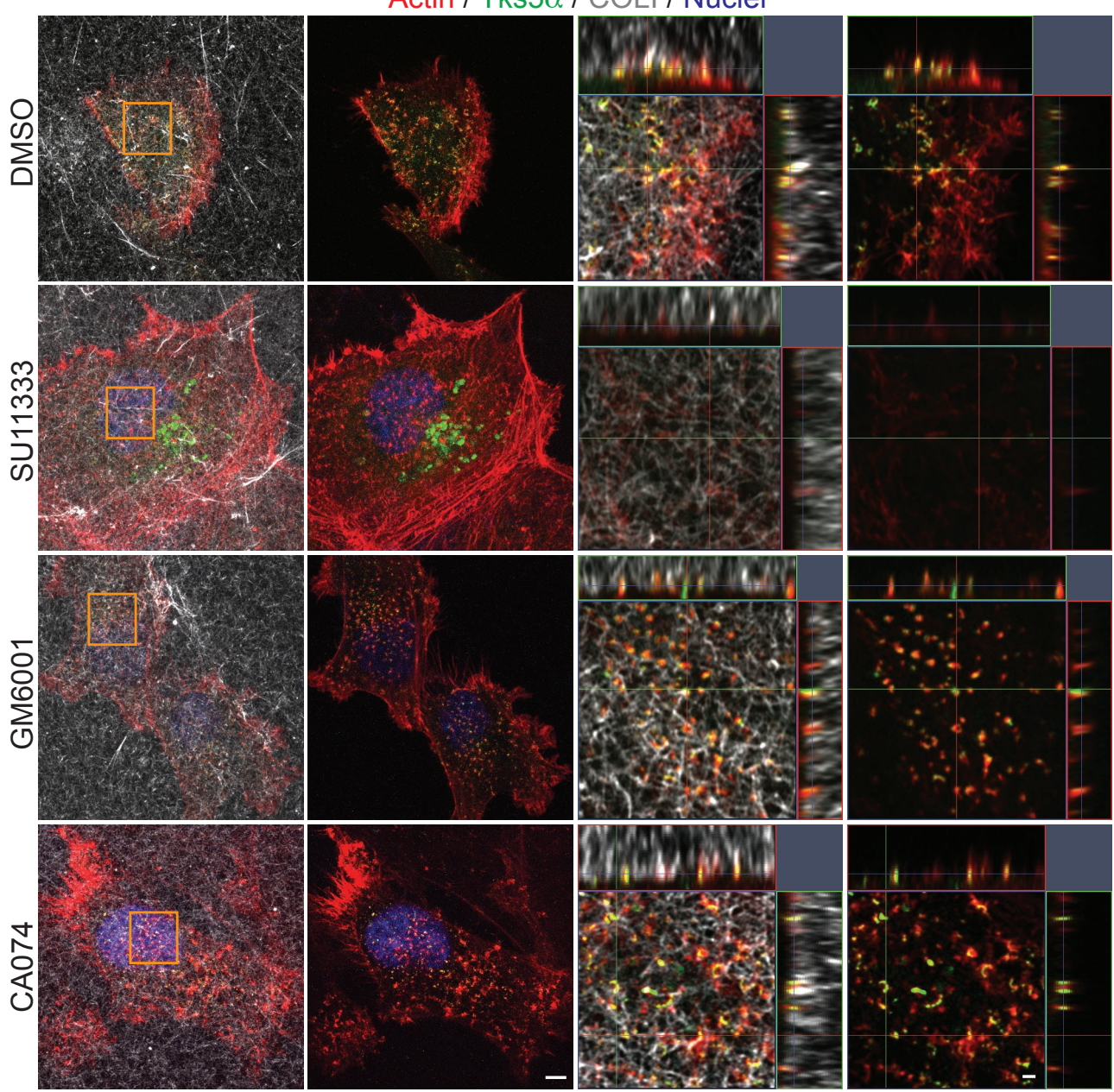

C
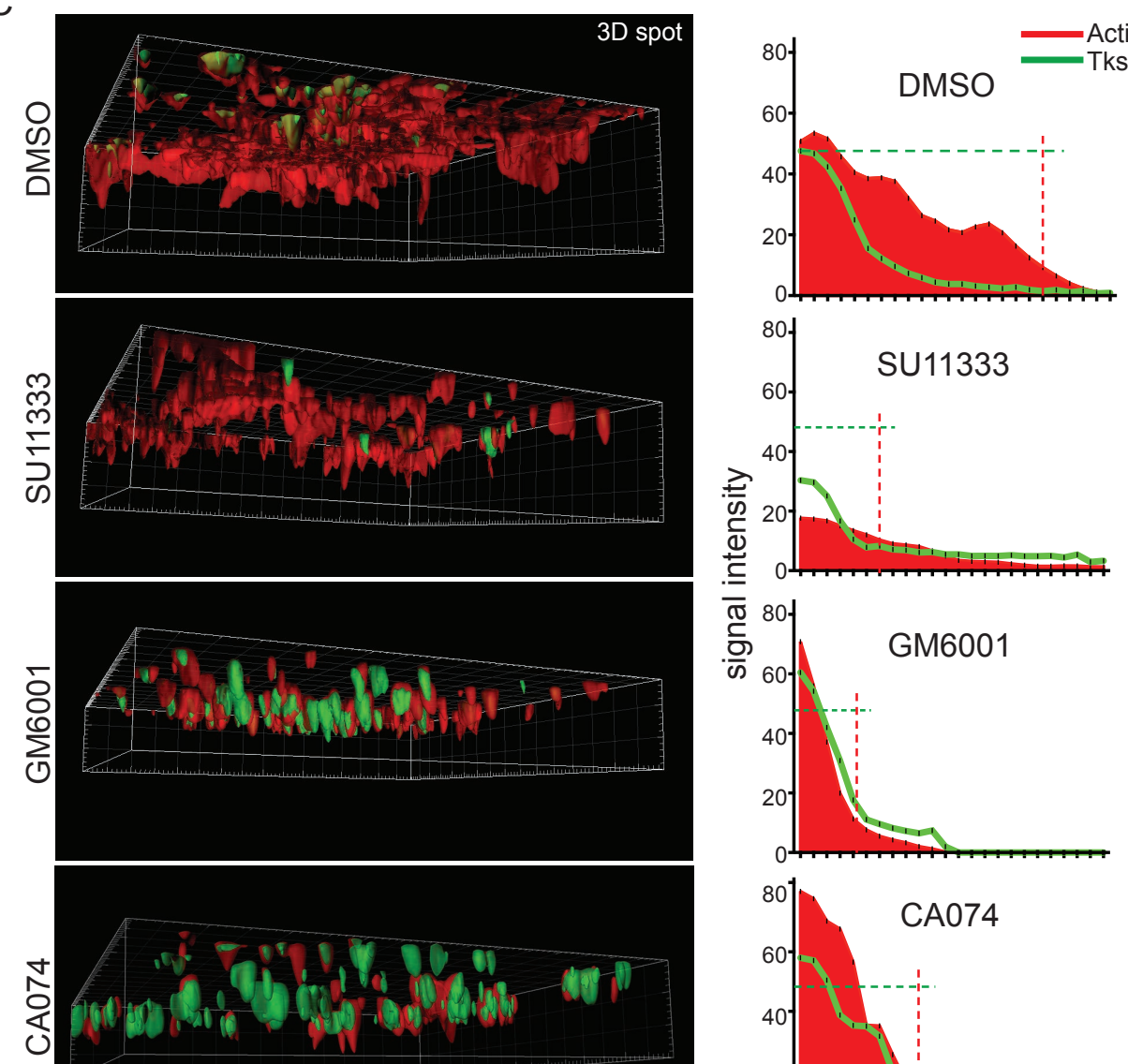

(19
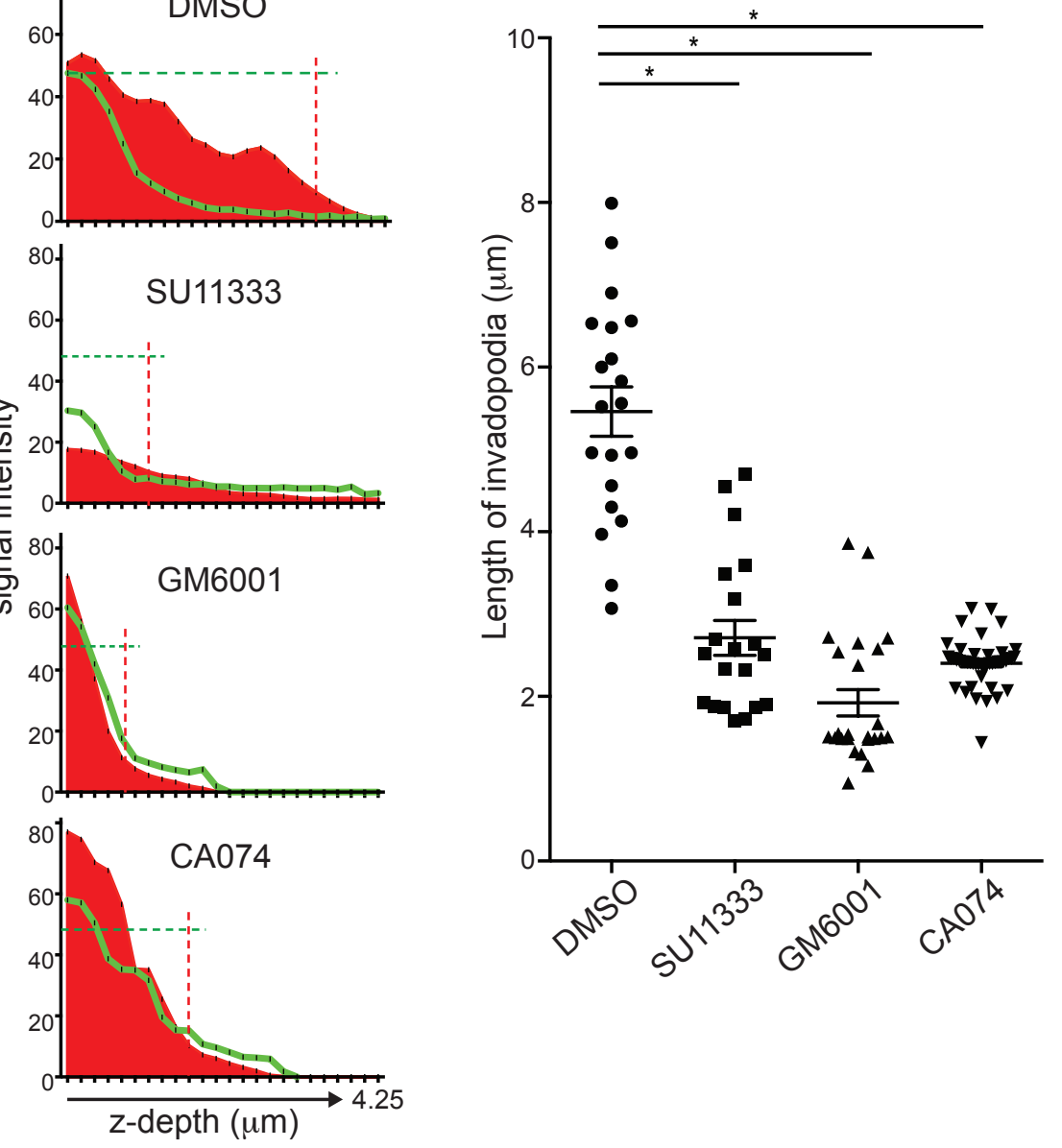

-

z-depth $(\mu \mathrm{m})$ 